Document downloaded from:

http://hdl.handle.net/10251/143788

This paper must be cited as:

Bertolesi, E.; Milani, G.; Carozzi, FG.; Poggi, C. (01-0). Ancient masonry arches and vaults strengthened with TRM, SRG and FRP composites: Numerical analyses. Composite Structures. 187:385-402. https://doi.org/10.1016/j.compstruct.2017.12.021

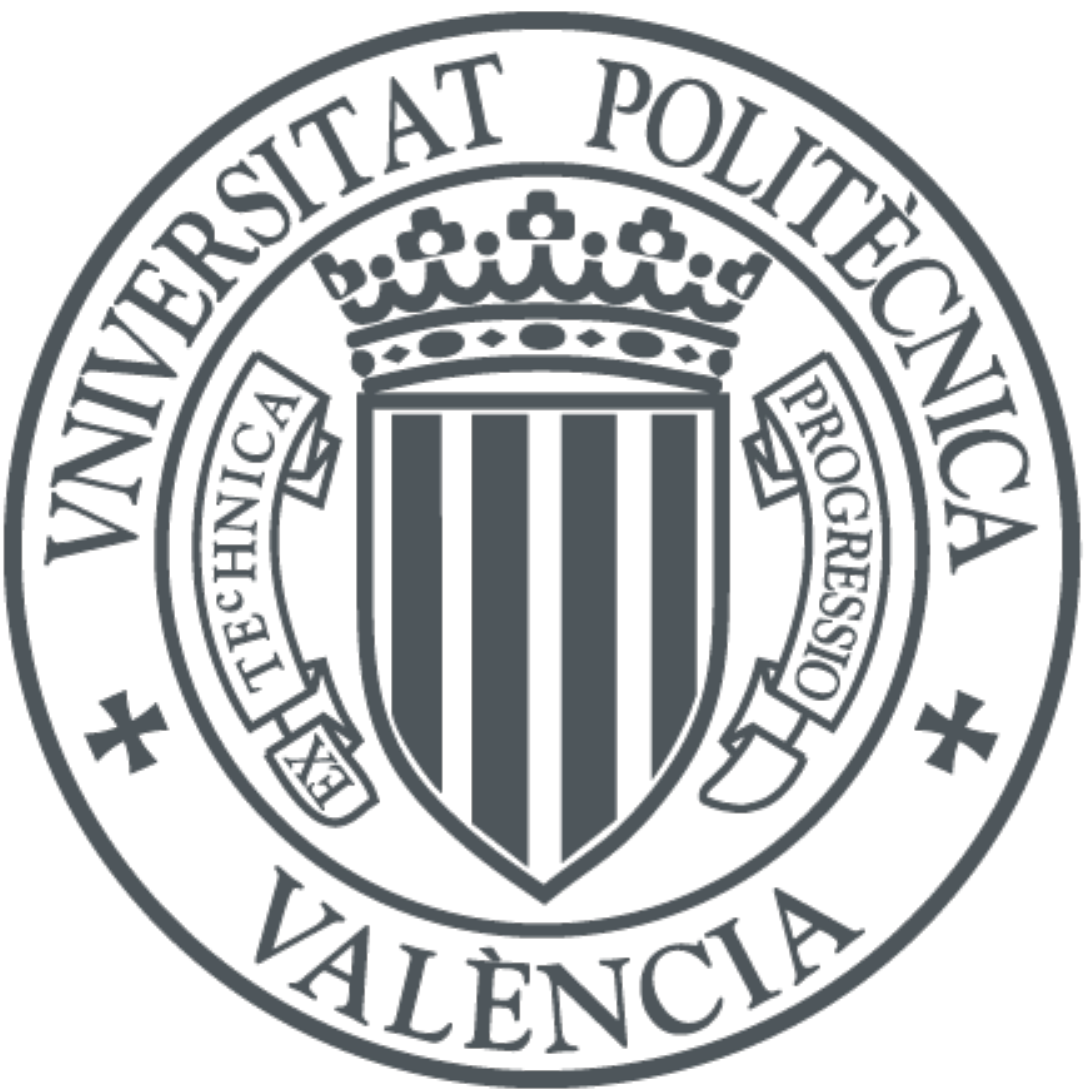

The final publication is available at

https://doi.org/10.1016/j.compstruct.2017.12.021

Copyright Elsevier

Additional Information 


\section{Accepted Manuscript}

Ancient masonry arches and vaults strengthened with TRM and FRP composites: Numerical analyses

Elisa Bertolesi, Gabriele Milani, Francesca Giulia Carozzi, Carlo Poggi

PII: S0263-8223(17)33586-9

DOI: https://doi.org/10.1016/j.compstruct.2017.12.021

Reference: COST 9178

To appear in:

\section{Composite Structures}

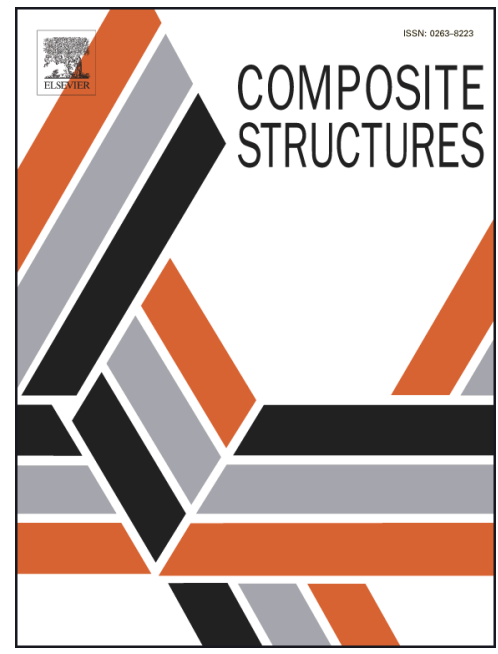

Received Date: $\quad 30$ October 2017

Revised Date: $\quad 29$ November 2017

Accepted Date: $\quad 11$ December 2017

Please cite this article as: Bertolesi, E., Milani, G., Giulia Carozzi, F., Poggi, C., Ancient masonry arches and vaults strengthened with TRM and FRP composites: Numerical analyses, Composite Structures (2017), doi: https://doi.org/ 10.1016/j.compstruct.2017.12.021

This is a PDF file of an unedited manuscript that has been accepted for publication. As a service to our customers we are providing this early version of the manuscript. The manuscript will undergo copyediting, typesetting, and review of the resulting proof before it is published in its final form. Please note that during the production process errors may be discovered which could affect the content, and all legal disclaimers that apply to the journal pertain. 


\title{
Ancient masonry arches and vaults strengthened with TRM and FRP composites: Numerical analyses
}

\author{
Elisa Bertolesi, Gabriele Milani ${ }^{1}$, Francesca Giulia Carozzi, Carlo Poggi \\ Department of Architecture, Built environment and Construction engineering ABC \\ Technical University of Milan \\ Piazza Leonardo da Vinci 32, 20133, Milan (Italy)
}

\begin{abstract}
The two arches and the three vaults experimentally described in [1] are here analyzed with a novel robust FE lower bound limit analysis code, suitable to predict active failure mechanisms, lines of thrust and collapse loads in absence and presence of TRM and FRP reinforcement. The approach relies into a discretization into rigid-infinitely resistant quadrilateral elements for masonry, interfaces between contiguous elements exhibiting limited strength and perfectly bonded rigid-plastic trusses representing the reinforcement. For masonry, a No Tension Material NTM model can be adopted to compare with classic Heyman's results, but also a limited compressive and tensile strength with a cohesive frictional behavior in shear may be accounted for in a relatively simple fashion, i.e. in principle with the possibility to model shear sliding and compression crushing. Debonding and delamination of the reinforcement are considered in a conventional way, assuming trusses with a limited tensile strength derived from either experimental data available or consolidated formulas from the literature. With the knowledge of the exact position of the hinges provided by limit analysis, 2D FE static analyses with non-linearity and softening concentrated exclusively on hinges are carried out, to simply extend the knowledge beyond collapse loads estimation towards a prediction of initial stiffness and ultimate displacements. In all cases, promising agreement with experiments is observed.
\end{abstract}

Keywords: masonry; arches and vaults; Textile Reinforced Mortar TRM; Fiber Reinforced Polymer FRP; Steel Reinforced Grout SRG; numerical modelling; LOwer BOund Limit Analysis (LOBOLA)

\section{Introduction}

Decades before the diffusion of personal computers, thrust line approach combined with limit analysis was considered the only effective tool for a fast assessment of the stability of masonry arches [2][3]. The quick diffusion in common practice of computer assisted structural programs has not changed the leading role played by the lower bound theorem of limit analysis, because of its intuitiveness and implementation easiness [4]-[6]. Nowadays, it can be affirmed that limit analysis, in both the lower and upper bound versions, is still a useful alternative to expensive non-linear FE simulations [7][8], as demonstrated by its extensive utilization for the safety assessment of masonry arches and vaults in general subjected to different loading conditions [9]-[15]. Its success is basically due to its simplicity, because it requires only a reduced number of material parameters, providing limit multipliers of loads, failure mechanisms and, at least on critical sections, the stress distribution at collapse. After the application of innovative strengthening materials (like FRP) for the vulnerability reduction of curved masonry elements [16]-[21] (mainly in Italy at the end of the 90s, after the 1997-1998 Umbria-Marche earthquake), computer assisted limit state approaches have been formulated also in presence of FRP reinforcement strips [22]-[36], see among the others Caporale et al. [23][29]-[31] or Roca et al. [24]. Again limit analysis -especially the lower bound- appears much more effective than a classic incremental FE approach [7][37], because is much faster and provides immediately the line of thrust at collapse, helping to understand how the flow of forces is transferred

\footnotetext{
${ }^{1}$ Corresponding author. E-mail: gabriele.milani@polimi.it
} 
from the external load to springing. On the other hand, non-linear complex damaging models [38][40] should be used for the analysis of FRP-reinforced masonry, because FRP delamination from the support is brittle. To some extent such considerations also apply to FRCM, even if a sufficient amount of experimentation is still lacking. Brittle is also the tensile behavior of mortar joints, therefore limit analysis, which is based on the assumption of perfect plasticity with infinite ductility, is not strictly applicable. This notwithstanding, if masonry tensile strength is neglected (as it classically occurs in No Tension Material NTM models) and reinforcement delamination is precluded or suitably considered in a convention way that accounts for debonding phenomenon, the application of either the virtual powers principle (kinematic approach) or the line of thrust method (static approach) still remains fascinating and probably the most powerful analytical tools to quickly predict load carrying capacity and position of hinges forming the failure mechanism. The evaluation of the ultimate load carrying capacity is one of the key issues for such type of constructions, because deformability is quite moderate. Literature is again relatively abundant in this regard and there are also some quite sophisticated approaches dealing with double curvature FEs and mesh adaptation schemes [11][13][35][36], but according to authors' knowledge, an in-situ experimentation combined with a FE lower bound limit analysis software for the prediction of failure loads and active failure mechanisms of reinforced arches is still lacking.

This paper is aimed at filling the gap in this regard, and it deals with the discussion of a robust and efficient FE lower bound limit analysis code suitable for the analysis of masonry arches of any geometry and reinforced in various ways. The unreinforced arch discretization is done using quadrilateral rigid-infinitely resistant elements interconnected by segmental interfaces where all internal dissipation can occur. On interfaces, even a NTM can be considered to compare directly with classic Heyman's results and check if the lines of thrust remain inside the thickness, but also a limited compressive and tensile strength with a cohesive frictional behavior in shear may be accounted for in a relatively simple fashion. It is therefore in principle possible to model both crushing in compression and sliding under shear loads. Reinforcement is modeled in a conventional but effective way by means of rigid-plastic trusses perfectly bonded to the underlying material, exhibiting an equivalent ultimate strength that suitably takes into account a debonding from the support and delamination, according to either consolidated literature in the field [38]-[41] or experimentation available [42]-[44].

The mathematical framework is therefore classic and collapse load, failure mechanism and thrust line can be estimated by means of a standard linear programming problem where failure multiplier is maximized, within the lower bound theorem of limit analysis, under equilibrium constraints and admissibility of the internal actions.

One of the major advantages of the lower bound approach proposed is that the geometry is directly imported from common CAD software and meshed within the commercial code Strand7. From the exact position of the hinges provided by limit analysis, 2D FE static analyses with non-linearity and softening concentrated exclusively on such hinges are carried out, in order to have information non only at failure, but extend the knowledge on the entire loading process in a quite straightforward manner, collecting interesting information on initial stiffness and ultimate displacements.

In addition, the quick assessment obtained with limit analysis of both expected collapse mechanism and ultimate load carrying capacity of existing structures, opens the way to the application of e.g. Bayesian inference [45], to account for uncertainty in material properties. Such latter approach may allow practitioners to reduce a relatively big scatter in material properties when new observations become available.

Experimental results presented in [1] are compared with those obtained by means of the present limit analysis approach, obtaining a satisfactory agreement on collapse loads in the unreinforced case, for both the arch and the vault. The assumption for masonry of a NTM hypothesis results slightly conservative, even if the prediction of the position of the hinges is fairly good. Sensitivity analysis are therefore conducted varying mortar tensile strength $\mathrm{f}_{\mathrm{t}}$ finding a perfect match with values sensibly small of $\mathrm{f}_{\mathrm{t}}$. With such values of strength for mortar joints, additional sensitivity analyses are carried 
out for the reinforced cases, varying the equivalent strength of the reinforcement $F_{b}$ and masonry compressive strength $f_{c}$. The aim is to find the conventional delamination strength of the reinforcement which allows a perfect match with the experimentally obtained collapse loads. Such procedure is useful to have an insight into the reliability of existing formulas on the maximum delamination strength (e.g. for FRP) and for an a-posteriori validation of future approaches, when they will become available (e.g. for FRCM). It is found that numerical collapse loads are generally in good agreement with experiments when literature data for the reinforcement strength are assumed.

\section{Lower bound limit analysis numerical validation}

As far as masonry arches and vaults (made by stones or solid clay bricks) are concerned, it can be affirmed that a sound theoretical background nowadays exists, see for instance Como [46] and Huerta [47], and that the modern theory of limit analysis of masonry structures, which has been developed mainly by Heyman [3][5] is the most reliable tool to understand and analyze masonry curved structures. For the sake of completeness, it is worth mentioning that the possibility of extending limit analysis theorems to no tension materials has been proved almost 20 years ago by Del Piero [48]. According to Heyman [3][5], limit analysis theorems can be applied to masonry provided the following three paramount conditions are verified, namely (1) infinite compressive strength, (2) no sliding between contiguous bricks, (3) vanishing tensile strength.

In the present paper, a lower bound limit analysis approach is proposed to deal with eventually reinforced masonry arches (Figure 1), where partially or all Heyman's hypotheses are removed. In other words, it can occur that the material is assumed able to withstand small but non zero tensile stresses, with possible crushing in compression and sliding of the blocks (observed in case of reinforced arches). 


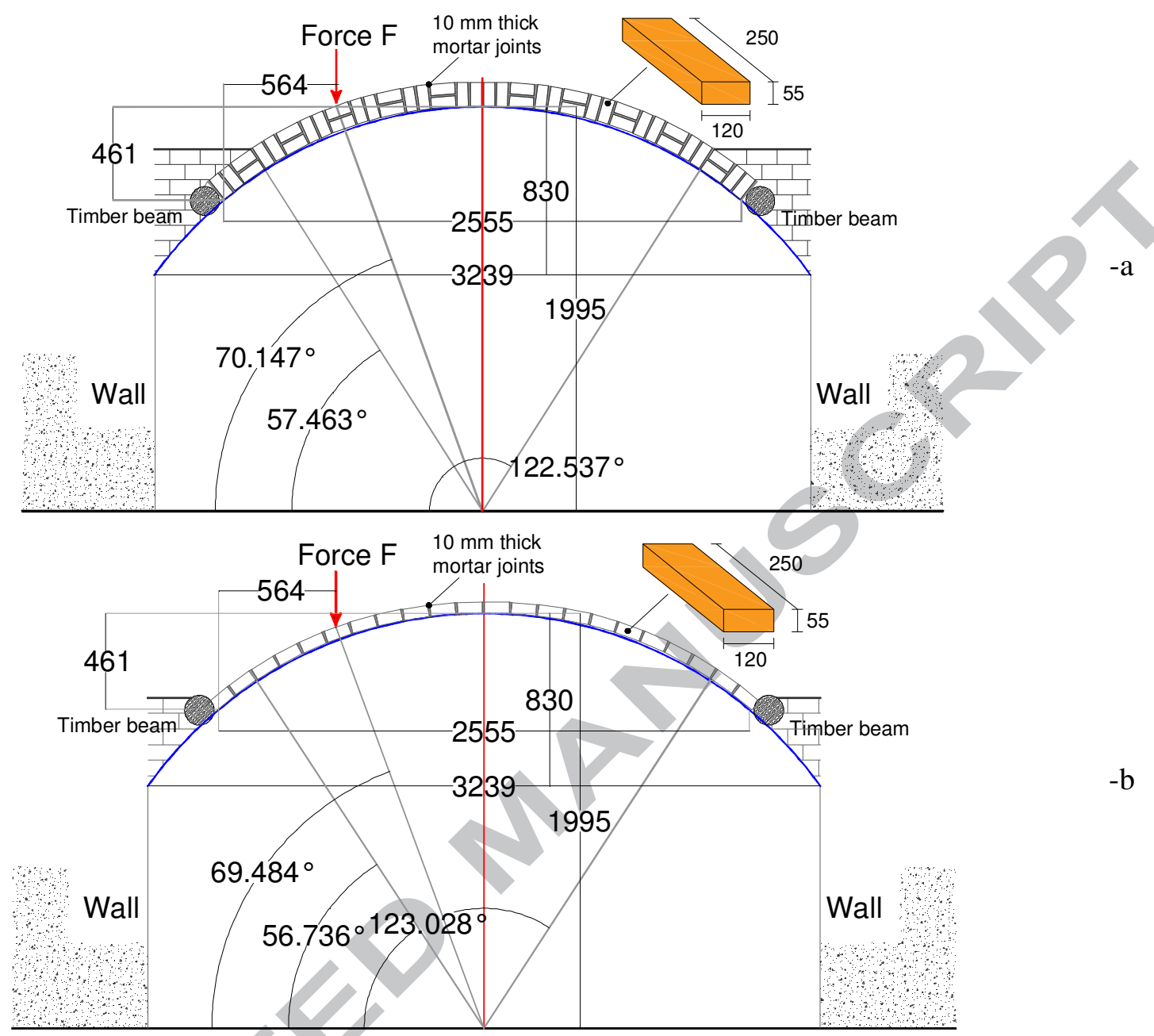

Figure 1: Geometry of the unreinforced and reinforced arches (-a) and barrel vaults (-b) (dimensions in $\mathrm{mm}$ ).

\subsection{The lower bound limit analysis approach proposed}

The lower bound approach proposed relies into a discretization made by infinitely resistant quadrilateral elements interconnected by interfaces where all plastic dissipation can occur, as schematically depicted in Figure 2. 

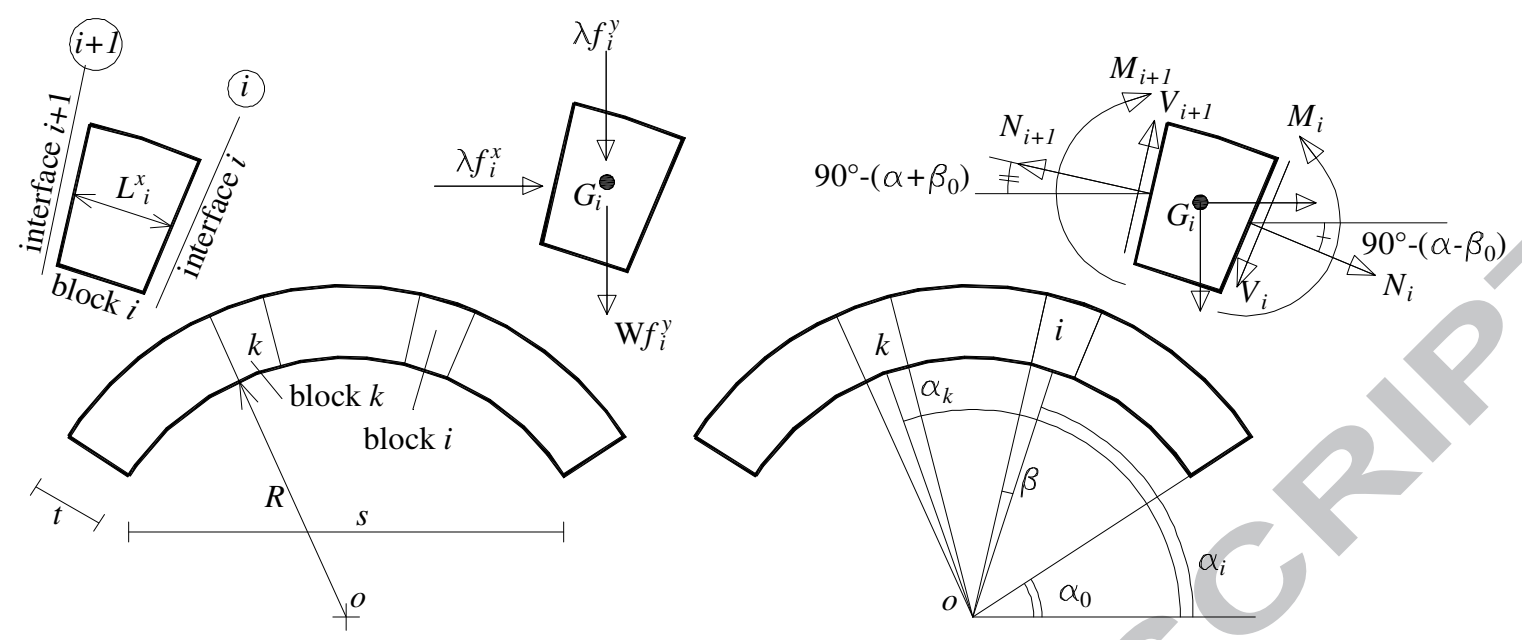

Figure 2: Lower bound FE discretization with rigid quadrilateral elements rigid-plastic interfaces.

If $N_{\text {sud }}$ is the number of quadrilateral elements used to discretize the arch, then $N_{\text {sud }}+1$ are the transversal sections where internal actions (namely axial load $N$, shear $V$ and bending moment $M$ ) must be evaluated. Total optimization unknowns, including the collapse multiplier, are therefore $3\left(N_{\text {sud }}+1\right)+1$.

\subsubsection{Equilibrium equations for each $\mathrm{FE}$}

Equilibrium equations must be written element by element. Considering the i-th element, the three equilibrium equations of each block can be written as follows:

$$
\begin{gathered}
N_{i} \sin \left(\alpha_{i}-\beta_{o}\right)-V_{i} \cos \left(\alpha_{i}-\beta_{o}\right)-N_{i+1} \sin \left(\alpha_{i}+\beta_{o}\right)+V_{i+1} \cos \left(\alpha_{i}+\beta_{o}\right)+\lambda f_{i}^{x}=0 \\
-N_{i} \cos \left(\alpha_{i}-\beta_{o}\right)-V_{i} \sin \left(\alpha_{i}-\beta_{o}\right)+N_{i+1} \cos \left(\alpha_{i}+\beta_{o}\right)+V_{i+1} \sin \left(\alpha_{i}+\beta_{o}\right)-W_{i}^{y}-\lambda f_{i}^{y}=0 \\
-\frac{V_{i} L_{i}^{x}}{2}+M_{i}-\frac{V_{i+1} L_{i}^{x}}{2}-M_{i+1}=0
\end{gathered}
$$

where all the symbols have been already introduced in Figure 2. Here it is worth only mentioning that Eq. ( 1 ) (a), (b) and (c) represent respectively the horizontal, vertical and rotational equilibrium around element centroid $G_{i}$.

Eq. ( 1 ) can be easily re-written in a compact matrix notation as follows:

$$
\left[\begin{array}{llllll}
\sin \left(\alpha_{i}-\beta_{o}\right) & -\cos \left(\alpha_{i}-\beta_{o}\right) & 0 & -\sin \left(\alpha_{i}+\beta_{o}\right) & \cos \left(\alpha_{i}+\beta_{o}\right) & 0 \\
-\cos \left(\alpha_{i}-\beta_{o}\right) & -\sin \left(\alpha_{i}-\beta_{o}\right) & 0 & \cos \left(\alpha_{i}+\beta_{o}\right) & \sin \left(\alpha_{i}+\beta_{o}\right) & 0 \\
0 & -\frac{L_{i}^{x}}{2} & 1 & 0 & -\frac{L_{i}^{x}}{2} & -1
\end{array}\right]\left[\begin{array}{c}
N_{i} \\
V_{i} \\
M_{i} \\
N_{i+1} \\
V_{i+1} \\
M_{i+1}
\end{array}\right]+\left[\begin{array}{c}
0 \\
-W_{i}^{y} \\
0
\end{array}\right]+\lambda\left[\begin{array}{c}
f_{i}^{x} \\
f_{i}^{y} \\
0
\end{array}\right]=0
$$

Eq. ( 2 ) can be further zipped as follows:

$$
\mathbf{G}_{i}^{e q}\left[\begin{array}{ll}
\mathbf{X}_{i}^{T} & \mathbf{X}_{i+1}^{T}
\end{array}\right]^{T}+\mathbf{W}_{i}+\lambda \mathbf{f}_{i}=0
$$

Where $\mathbf{G}_{i}^{e q}$ is a $3 \times 6$ matrix that collects only some geometric features of the i-th block, $\left[\begin{array}{ll}\mathbf{X}_{i}^{T} & \mathbf{X}_{i+1}^{T}\end{array}\right]^{T}$ is the vector on internal actions on i-th and i+1-th interface, $\mathbf{W}_{i}$ is the vector of loads 
independent from the load multiplier action on the i-th elements, $\lambda$ is the collapse multiplier and $\mathbf{f}_{i}$ is the vector of unitary loads dependent on the load multiplier.

\subsubsection{Inequality constraints and strength domains for unreinforced interfaces}

Inequality constraints, securing admissibility of the equilibrated stress field in the framework of the lower bound theorem of limit analysis, should be written interface by interface. There are basically four cases that can be encountered in common numerical modelling, see also Figure 3, namely (A) tensile strength strictly zero and infinite compressive strength (pure NTM model), (B) tensile strength small but non-zero and infinite compressive strength, (C) small tensile strength and finite compressive strength and (D) a combination of the previous cases but with finite shear strength, obeying a Mohr-Coulomb law.

In the first case, (Figure 3 Case A) limit equilibrium on active hinges is obtained with the axial load (i.e. the line of thrust) passing through the extremes of the interface, either at the intrados or at the extrados. This property, which reduces to a geometric constraint on the line of thrust, was made famous by Heyman [3][5], who was one of the first authors theorizing that the line of thrust must always lay inside the arch thickness, with four tangencies conditions in presence of incipient collapse. However, it is worth mentioning that such conclusion does not hold strictly in case of nonzero tensile strength, i.e. for Case B. Case C is more complex, because the strength domain becomes non-linear in presence of finite compressive strength. Finally, Case D generalizes the arch problem to a lower bound limit analysis on a curved structure where also sliding is possible. Typically, sliding does not occur for unreinforced arches, but the application of a strengthening system could make such failure mode more probable. Whilst sliding would require the utilization of non-associated limit analysis, it has been shown that the prediction done by classic associated limit analysis on collapse loads and failure mechanisms active is technically acceptable.

In the first case, (Figure 3 Case A) the eccentricity of the normal compressive force, intended as the ratio between $\mathrm{M}$ and $\mathrm{N}$ cannot exceed $\mathrm{t} / 2$, meaning that the interface strength domain boundary is constituted by two straight lines, symmetrically disposed with respect to the horizontal axis (where normal action $\mathrm{N}$ is represented). The strength domain is therefore represented by the following linear inequalities:

$$
\frac{t}{2} N_{i}+M_{i} \leq 0 \quad \frac{t}{2} N_{i}-M_{i} \leq 0
$$

When a non-zero tensile strength is introduced (Figure 3 Case B), again two linear constraints per interface are obtained, but with the origin strictly inside the strength domain:

$$
\frac{t}{2} N_{i}+M_{i} \leq f_{t} \frac{t^{2}}{2} \quad \frac{t}{2} N_{i}-M_{i} \leq f_{t} \frac{t^{2}}{2}
$$

Such latter property is paramount to strengthen the stability of any LP solver, because in classic limit analysis the case of the origin on the boundary of the strength domain is in principle excluded. In case of finite compressive strength, see Case $\mathrm{C}$ in Figure 3, the domain is symmetrically bounded with respect to the horizontal axis by means of two parabolas. The resultant strength domain is therefore non linear and represented by the following two non-linear inequalities:

$$
\begin{aligned}
& \frac{N_{i}^{2}}{2\left(f_{c}+f_{t}\right)}+\frac{t}{2} \frac{f_{c}-f_{t}}{f_{c}+f_{t}} N_{i}+M_{i} \leq \frac{t^{2}}{2} \frac{f_{c} f_{t}}{f_{c}+f_{t}} \\
& \frac{N_{i}^{2}}{2\left(f_{c}+f_{t}\right)}+\frac{t}{2} \frac{f_{c}-f_{t}}{f_{c}+f_{t}} N_{i}-M_{i} \leq \frac{t^{2}}{2} \frac{f_{c} f_{t}}{f_{c}+f_{t}}
\end{aligned}
$$

Finally in Case D the Mohr-Coulomb finite shear strength must be added to previous equations, introducing two further inequality constraints as follows: 


$$
\begin{aligned}
& V_{i}+N_{i} \tan \Phi \leq c t \\
& -V_{i}+N_{i} \tan \Phi \leq c t
\end{aligned}
$$

Where $\Phi$ is the friction angle and $c$ the cohesion.

Dealing for the sake of simplicity only with linear inequality constraints, then ( 4 ) and ( 5 ) can be again put in compact matrix notation as follows:

$$
\left[\begin{array}{ccc}
\frac{t}{2} & 0 & 1 \\
\frac{t}{2} & 0 & -1
\end{array}\right]\left[\begin{array}{c}
N_{i} \\
V_{i} \\
M_{i}
\end{array}\right] \leq f_{t} \frac{t^{2}}{2}\left[\begin{array}{l}
1 \\
1
\end{array}\right] \Rightarrow \mathbf{G}_{i}^{i n} \mathbf{X}_{i} \leq \mathbf{b}_{i}^{i n}
$$

Where $\mathbf{G}_{i}^{\text {in }}$ is a $2 \times 3$ matrix that collects only some geometric features of the i-th block, $\mathbf{b}_{i}^{\text {in }}$ is a $2 \times 1$ vector collecting inequalities right hand sides and all other symbols have been already introduced. From ( 3 ) and ( 8 ) the assemblage into global equality $\mathbf{A}^{e q}$ and inequality $\mathbf{A}^{\text {in }}$ matrices is very straightforward, being both block band matrices.

The objective function is represented by the collapse multiplier $\lambda$, that, in the framework of the static theorem of limit analysis (lower bound), has to be maximized. In matrix notation, denoting with $\mathbf{X}$ the $3\left(N_{\text {sud }}+1\right)+1$ column vector of global unknowns, and with $\mathbf{O}_{b}$ a $3\left(N_{\text {sud }}+1\right)+1$ column vector of all zeros except the last cell $(=1)$, then the objective function is $\mathbf{O}_{b}{ }^{T} \mathbf{X}$. 

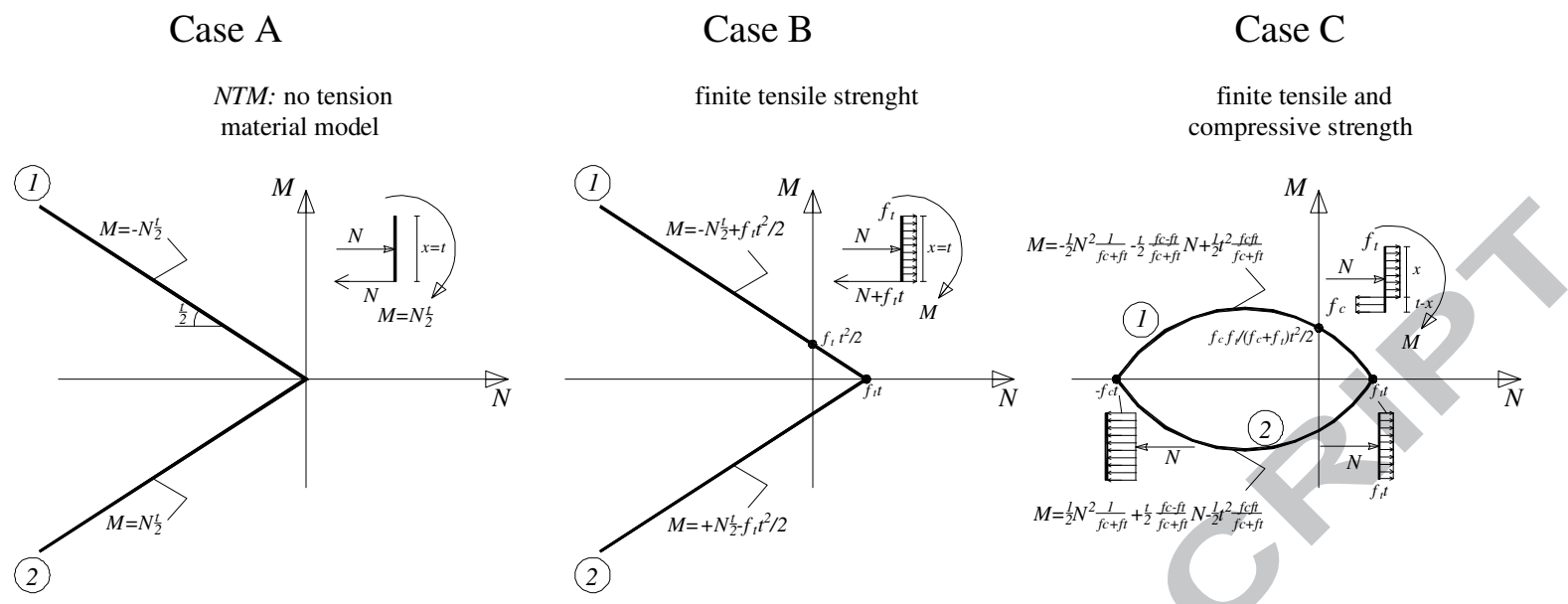

Figure 3: Different strength domains that can be adopted to analyze unreinforced masonry arches. Case A: infinite compression strength, zero tensile strength. Case B: infinite compressive strenght and finite tensile strength. Case C: finite compressive and tensile strength.
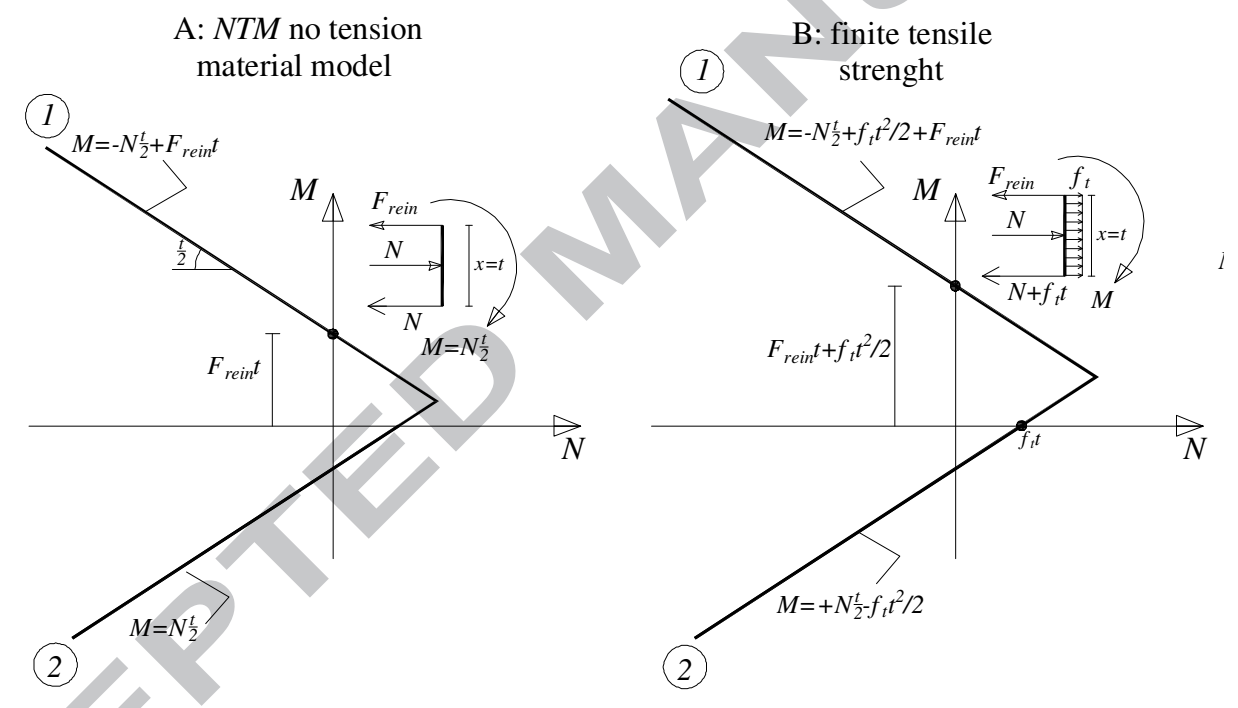

Figure 4: Different strength domains that can be adopted to analyze masonry arches reinforced at the extrados. Case A: infinite compression strength, zero tensile strength. Case B: infinite compressive strenght and finite tensile strength.

\subsubsection{Inequality constraints in case of strengthening}

When a strengthening system is applied at the extrados surface, as in the case here analyzed, then the strength domain expands not symmetrically, as shown in Figure 4. In Figure 4 with $F_{\text {rein }}=A_{\text {rein }} f_{\text {fdd }}$ we indicate the ultimate force that the reinforcement is able to transfer to the substrate, having denoted with $A_{\text {rein }}$ the cross area of reinforcement and with $f_{\text {fdd }}$ the equivalent tensile strength, which eventually takes into account debonding phenomena.

In case of non-zero tensile strength of the mortar joint (which comprises also the NTM model when $f_{t}$ is set to zero), the two linear constraints per interface to write are the following:

$\frac{t}{2} N_{i}+M_{i} \leq f_{t} \frac{t^{2}}{2}+F_{\text {rein }} t \quad \frac{t}{2} N_{i}-M_{i} \leq f_{t} \frac{t^{2}}{2}$ 


\subsection{The LP problem, related numerical issues and post-processing results}

The linear programming (LP) problem obtained is the following:

$$
\begin{aligned}
& \max \lambda=\mathbf{O}_{b} \mathbf{X} \\
& \text { s.t. }\left\{\begin{array}{l}
\mathbf{A}_{e q} \mathbf{X}=\mathbf{b}_{e q} \\
\mathbf{A}_{i n} \mathbf{X} \leq \mathbf{b}_{i n}
\end{array}\right.
\end{aligned}
$$

Where $\mathbf{A}_{e q} \mathbf{X}=\mathbf{b}_{e q}$ is a set of $3 N_{\text {sud }}$ equalities representing the equilibrium of the single elements and $\mathbf{A}_{\text {in }} \mathbf{X} \leq \mathbf{b}_{\text {in }}$ is a set of $2\left(N_{\text {sud }}+1\right)$ inequalities representing the admissibility of the internal actions.

It is worth mentioning that LP problem ( 10 ) is a small/medium scale one, but sparse matrix technology and a classic interior point algorithm IP is preferred to reduce the computational time needed.

In case of finite compressive strength of the joint, inequality constraints need to be linearized. One straightforward option is to use a piecewise linear approximation, as proposed by many authors in the past, see for instance [49][50]. Nowadays, codes are so efficient that IP algorithms can handle thousands of variables and constraints, therefore no particular problems arise, but the convergence of the solution obtained should be checked progressively increasing the number of planes of the approximation. An alternative, already proposed in [51] but in another context, is to use an iterative procedure based on the simplex method. As a matter of fact, simplex finds always the solution on a corner of the domain. Therefore, it is possible to use a very rough approximation of the strength domain in the starting step and refine the approximation of the strength domain only in the vicinity of the actual solution, as shown in Figure 5. The drawback is that the solution found is not strictly a lower bound, because strength domain is approximated with tangent planes.
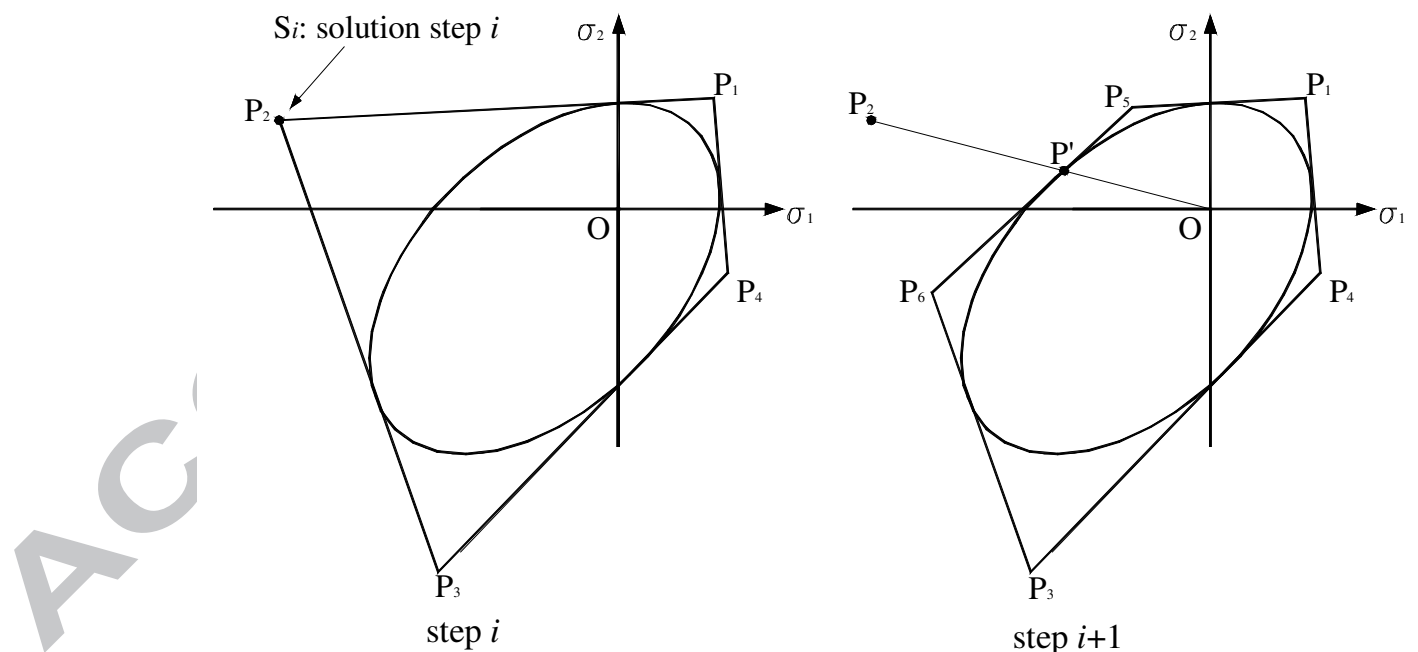

Figure 5: Iterative algorithm used in case of finite compressive strength and step by step linearization of the non-linear inequalities.

The identification of the line of thrust occurs point by point evaluating the eccentricity of the normal action on the i-th section as $e_{i}=M_{i} / N_{i}$ and connecting the dots. It is worth mentioning that, in the present work, we subdivided the arch into 100 sections before the point of application of 
the load and 100 sections after. Such points have been adopted to construct the unreinforced and reinforced lines of thrust.

The limits where the line of thrust can lay depend on the hypotheses done for the material and if reinforcement is present. We distinguish the following three cases:

1) Unreinforced case, NTM model. From Eq. ( 4 ) the line of thrust must lay within arch thickness, i.e. $-\frac{t}{2} \leq e_{i} \leq \frac{t}{2}$

2) Unreinforced case, model with non-zero tensile strength. From Eq. ( 5 ) the line of thrust must lay within arch thickness, i.e. $-\frac{t}{2}\left(1-\frac{f_{t} t}{N_{i}}\right) \leq e_{i} \leq \frac{t}{2}\left(1-\frac{f_{t} t}{N_{i}}\right)$. It is worth noting that in this case eccentricity upper and lower bounds depend on the local value of $N_{i}$;

3) Reinforced case, model with non-zero tensile strength. From Eq. ( 9 ), it is straightforward to deduce that $-\frac{t}{2}\left[1-\frac{\left(f_{t} t+\frac{1}{2} F_{\text {rein }}\right)}{N_{i}}\right] \leq e_{i} \leq \frac{t}{2}\left(1-\frac{f_{t} t}{N_{i}}\right)$. Again, eccentricity upper and lower bounds depend on the local value of $N_{i}$.

4) When a limited shear strength is assumed, the concept of thrust line partially loses its efficacy, because failure can be the result of a mechanization due to the presence of both flexural hinges and sliding interfaces.

The identification of the plastic hinges and sliding interfaces can be done in two alternative manners, the first simply solving the dual of LP problem ( 10 ), the latter substituting the solution vector found in $\mathbf{A}_{\text {in }} \mathbf{X} \leq \mathbf{b}_{\text {in }}$ and checking what are the inequality constraints active.

\section{Discussion of the numerical results obtained}

In this Section, a comprehensive discussion of the numerical results obtained applying the FE LB limit analysis approach previously presented is reported. Particular emphasis is given to the value of masonry tensile strength to assign in the unreinforced case and the equivalent ultimate strength of the strengthening system in the reinforced case to fit perfectly experimental collapse loads. Obviously such approach would make much more sense in case of different tested replicates, a scenario difficultly obtainable for in-situ experimentation, where samples are typically a few or even unique.

\subsection{Unreinforced arch U_A}

Line of thrust obtained for the unreinforced arch U_A at progressively increased values of masonry tensile strength ( $f_{t}$ from $0.001 \mathrm{MPa}$, an excellent approximation of the NTM model, to $0.1 \mathrm{MPa}$ ) with position of the plastic hinges and the admissible region of the thrust line is shown in Figure 6 from -a to -h. In Figure 7-a the same line of thrust in case of no-tension material is compared with that obtained with a refined 2D elasto-plastic FE model. In Figure 7-b a precise identification of hinges position as a function of angle $180^{\circ}-\alpha$ is provided, whereas in subfigure $-\mathrm{c}$ the corresponding failure mechanism is depicted. As can be noted from an analysis of both figures, the line of thrust is all contained within the arch thickness in case of the NTM hypothesis, whereas the bounds progressively go outside for higher values of $f_{t}$. Especially for $f_{t}=0.1 \mathrm{MPa}$ it is particularly 
evident the dependence of such bounds on the value of normal action found in the equilibrated solution. Not surprisingly, also, the position of the four hinges forming the mechanisms remains unaltered.

Figure 8-a shows a sensitivity analysis of the collapse load progressively increasing $f_{t}$, assuming for masonry an infinite compressive strength. As expected, the increase is linear, because the strength domain proportionally grows increasing $f_{t}$ (and compressive strength is infinite), but it is interesting to notice that the exact experimental collapse load is obtained with an $f_{t}$ equal to 0.0077 $\mathrm{MPa}$, which is certainly a very low tensile strength but not enough to consider reliable the NTM model, because it allows an increase of the collapse load from 1.725 to $2.3 \mathrm{kN}$. Figure $8-\mathrm{b}$ shows the same results, but with different values for the assumed compressive strength. As expected, it is necessary to make the hypothesis of quite low strength in compression (lower than $2 \mathrm{MPa}$ ) to obtain results deviating in a perceivable manner from those obtained with infinite resistance.

In order to have a further insight into the role played by $f_{t}$, several elasto-plastic analyses with the commercial code Strand7 are performed, assuming the arch elastic everywhere and concentrating non linearity on the four hinges with position found with limit analysis. Cutoff bars with elastoplastic behavior in tension are used at this aim, setting for them different tensile strengths for the different cases analyzed (namely $f_{t}=0.007,0.015$ and $0.02 \mathrm{MPa}$ ). In order to lock shear lability on plastic hinges, shear elastic elements are also added, having the same elastic properties of the surrounding masonry. Stress-strain relationships for cutoff bars, masonry plate and shell elements and eventually trusses representing the reinforcement are schematically depicted in Figure 9. The results obtained are shown in Figure 10-a. As expected, collapse loads found with limit analysis are quite accurately reproduced, but it is also possible to estimate rather quickly and with sufficient accuracy the deformability of the arch, an information not achievable with limit analysis. Another important result is the knowledge of the sequence of hinges formation, summarized in Figure 10-b and in more detail in Figure 11. Such information may be particularly useful when dealing with the reinforcement of partially damaged arches, i.e. where the expected increase of the load carrying capacity cannot be evaluated with limit analysis on an undamaged structure. In this regard, therefore, limit analysis can be quite useful only to set mechanical parameters at failure and to roughly predict the position of the plastic hinges. With such information, simple FE codes, basically elastic everywhere exception made for the plastic hinges can be used to predict quickly and efficiently displacements near failure and compare with the overall experimental force-displacement curves. 
Revised version, modifications highlighted in color YELLOW

\section{$f_{t}=0.001 \mathrm{MPa}$}
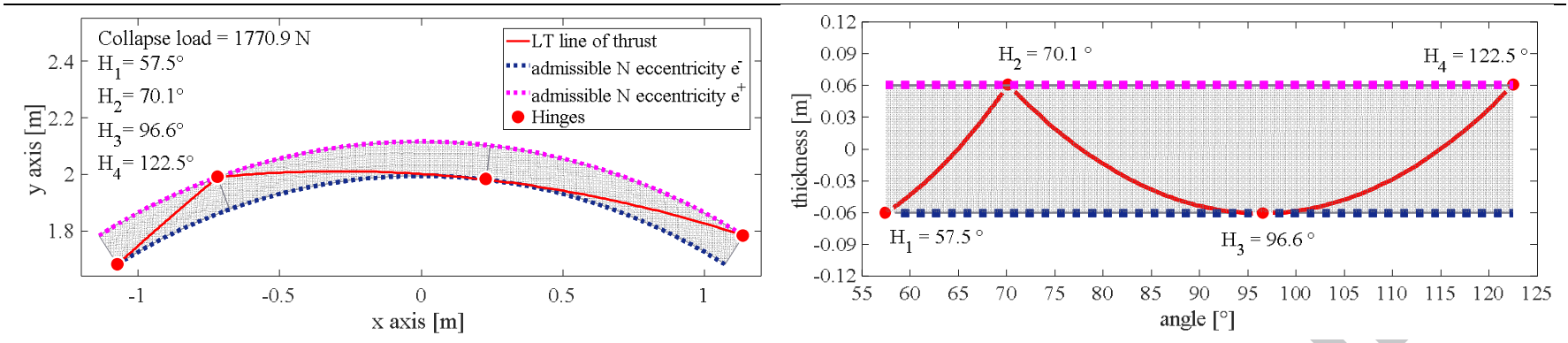

$-\mathrm{a}$

$-b$

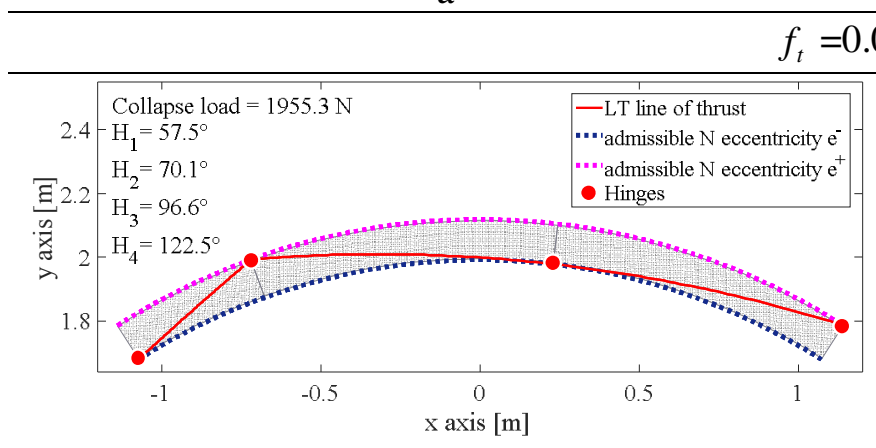

$-\mathrm{c}$

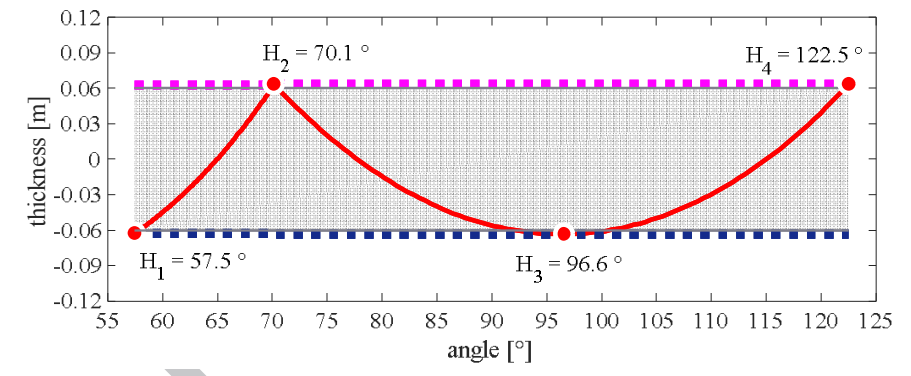

$-d$

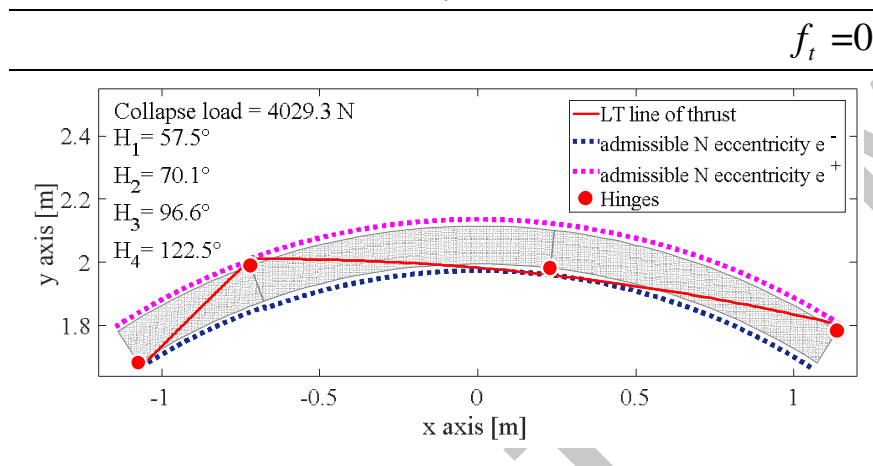

$f_{t}=0.05 \mathrm{MPa}$
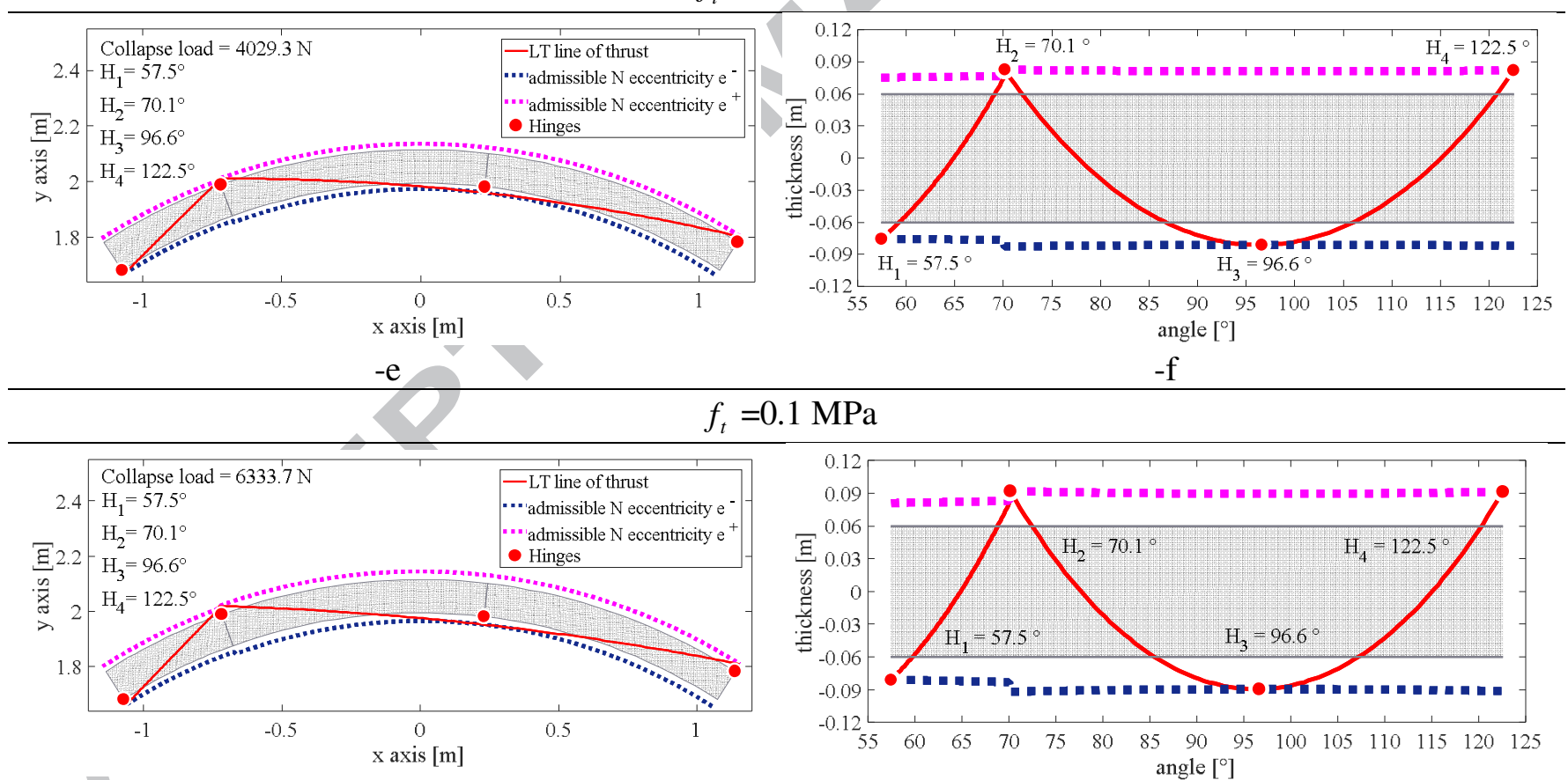

$-\mathrm{g}$

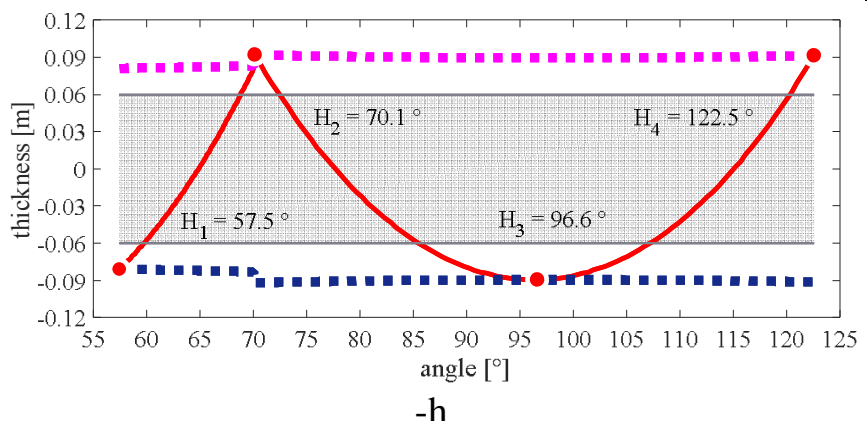

Figure 6: Unreinforced arch U_A. -a, $-\mathrm{c},-\mathrm{e},-\mathrm{g}$ : lines of thrust at different vaules of masonry tensile strength. $-\mathrm{b},-\mathrm{d},-\mathrm{f},-\mathrm{h}$ : identification of hinges position as a function of angle $180^{\circ}-\alpha$. 
Revised version, modifications highlighted in color YELLOW

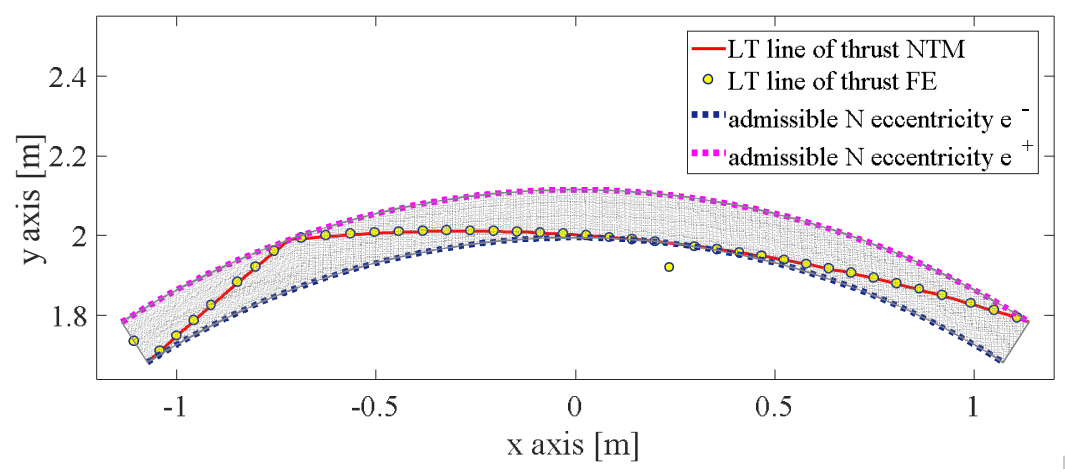

NTM
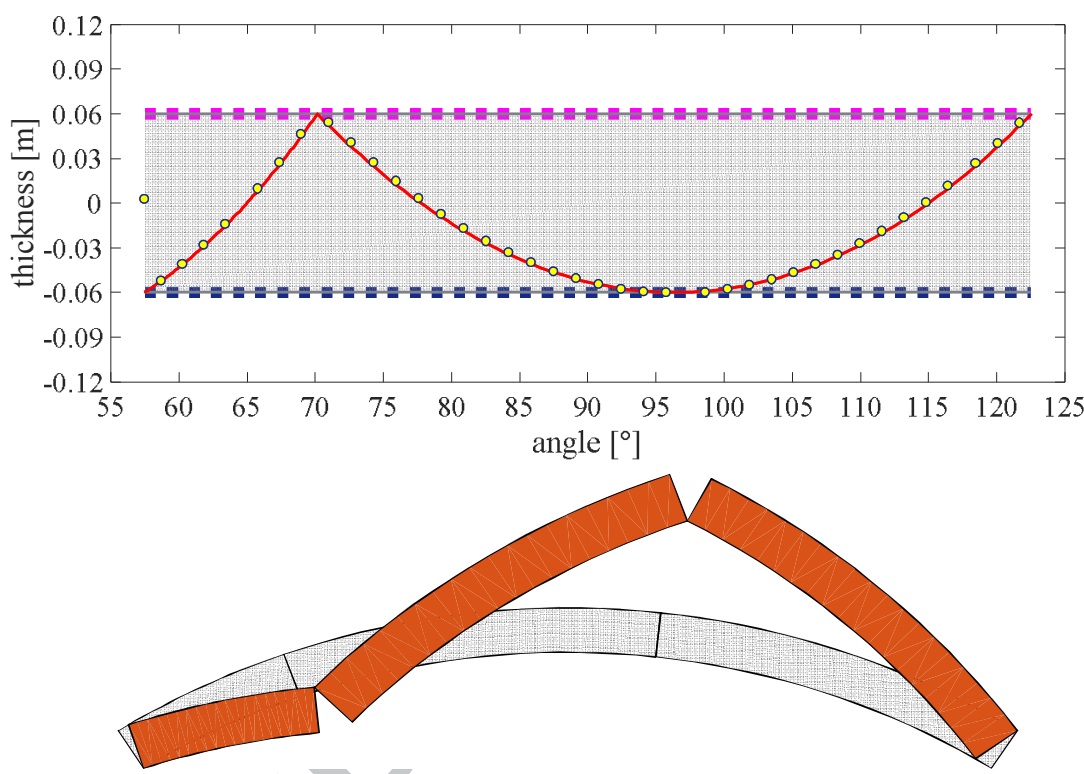

Figure 7: Unreinforced arch U_A in case of no-tension material. -a: line of thrust at different vaules of masonry tensile strength. -b: identification of hinges position as a function of angle $180^{\circ}-\alpha$ and corresponding failure mechanism $(-\mathrm{c})$. 
Revised version, modifications highlighted in color YELLOW
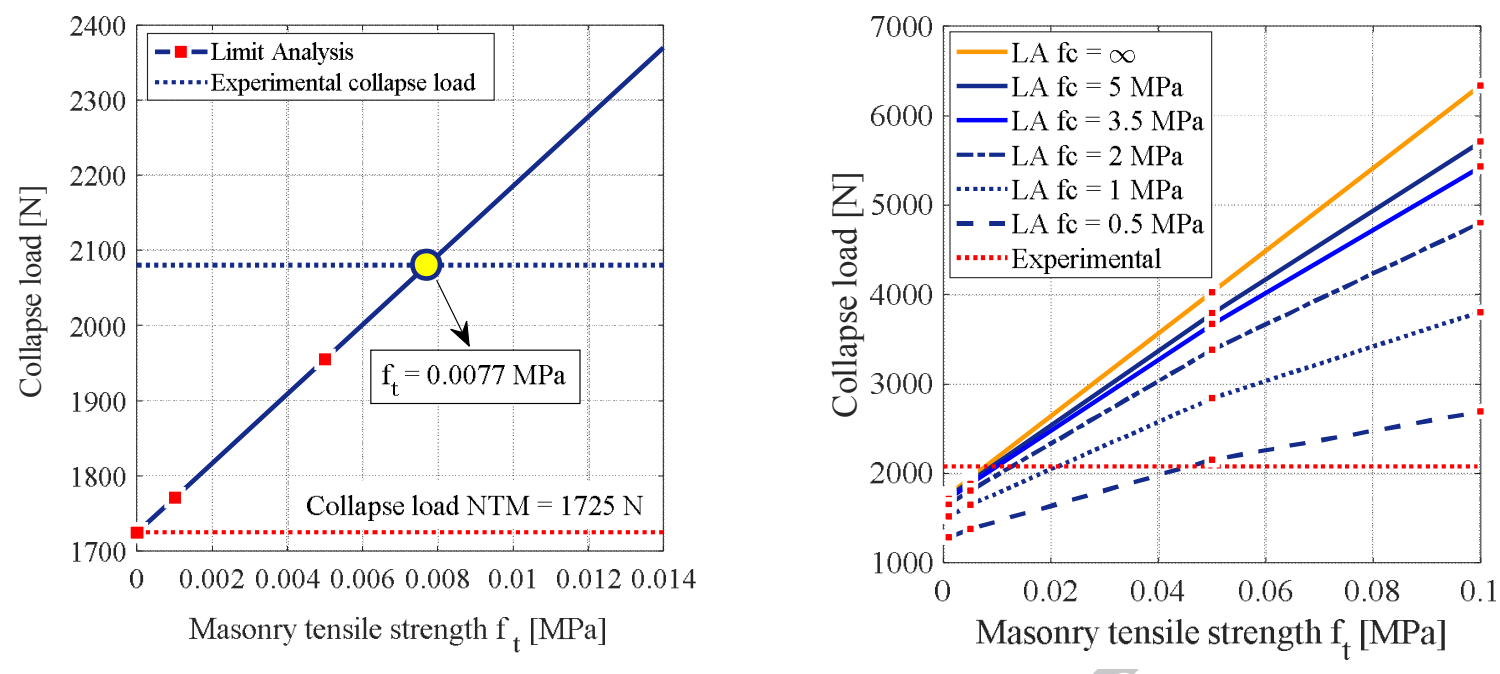

$-a$

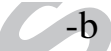

Figure 8: Unreinforced arch U_A: sensitivity analyses on the collapse load changing masonry tensile strength. $-\mathrm{a}$ : infinite compressive strength. $-\mathrm{b}$ : finite compressive strength. 


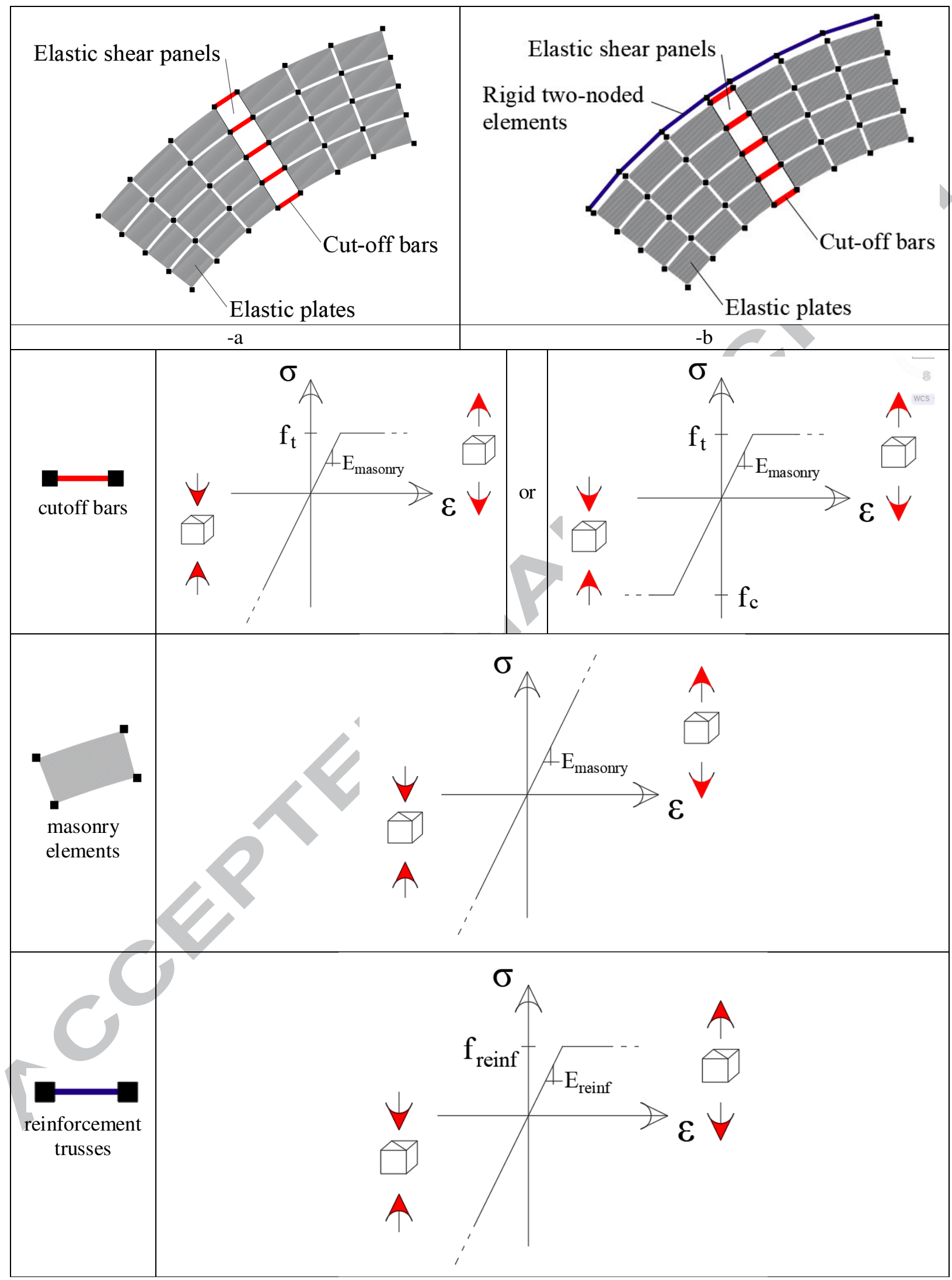

Figure 9: Stress-strain relationships adopted in the FE Strand7 model for cutoff bars, masonry elements and reinforcement 


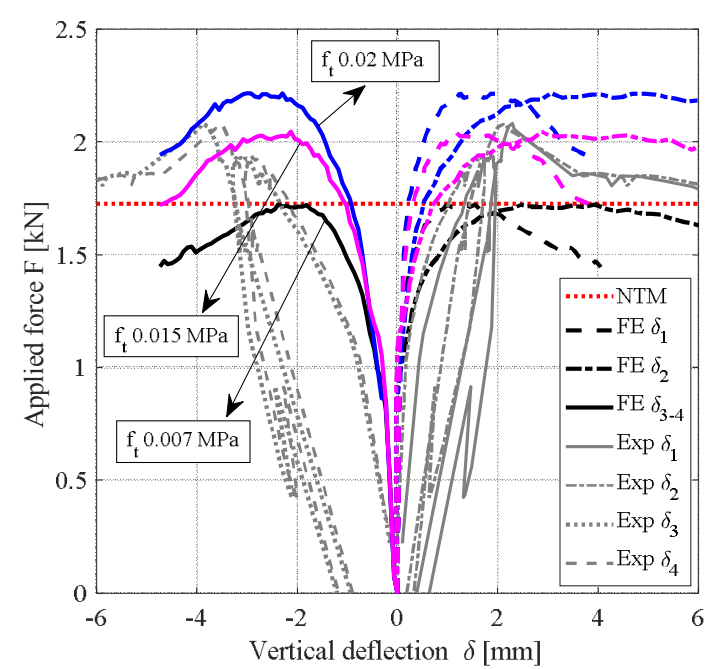

$-\mathrm{a}$

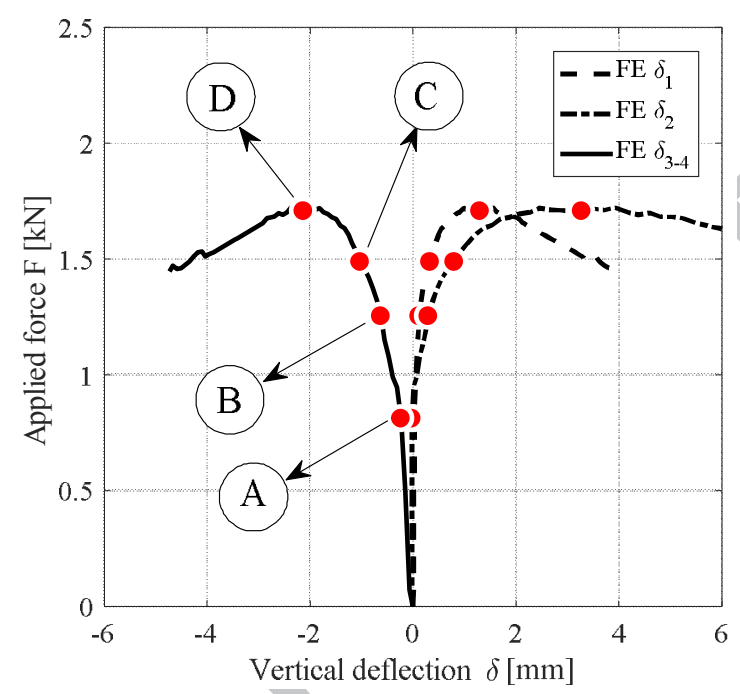

$-b$

Figure 10: Unreinforced arch U_A: utilization of an elasto plastic FE approach with plastic hinges located on positions found by LA. -a: comparison with experimental data; -b: steps of formation of the hinges. 


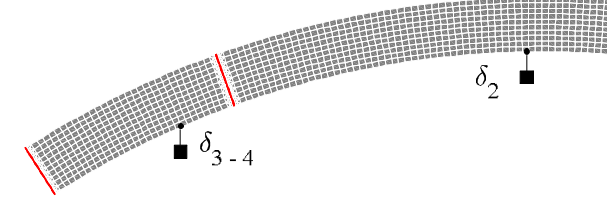

A

Scale factor: 200

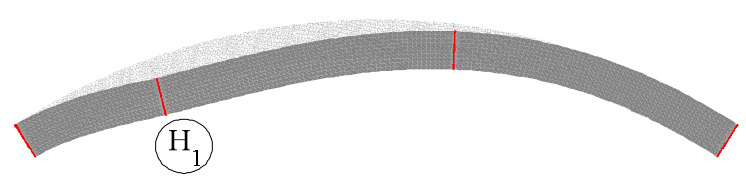

$-b$

C

Scale factor: 150

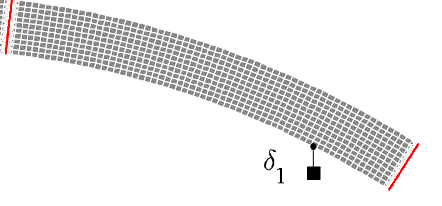

B

Scale factor: 200

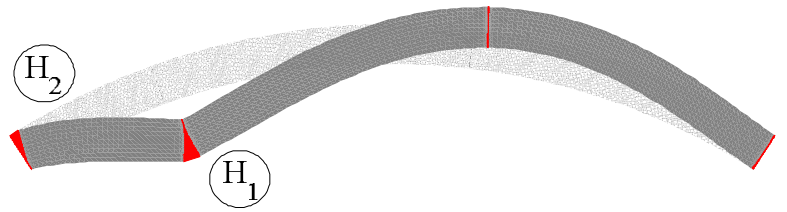

D

Scale factor: 50

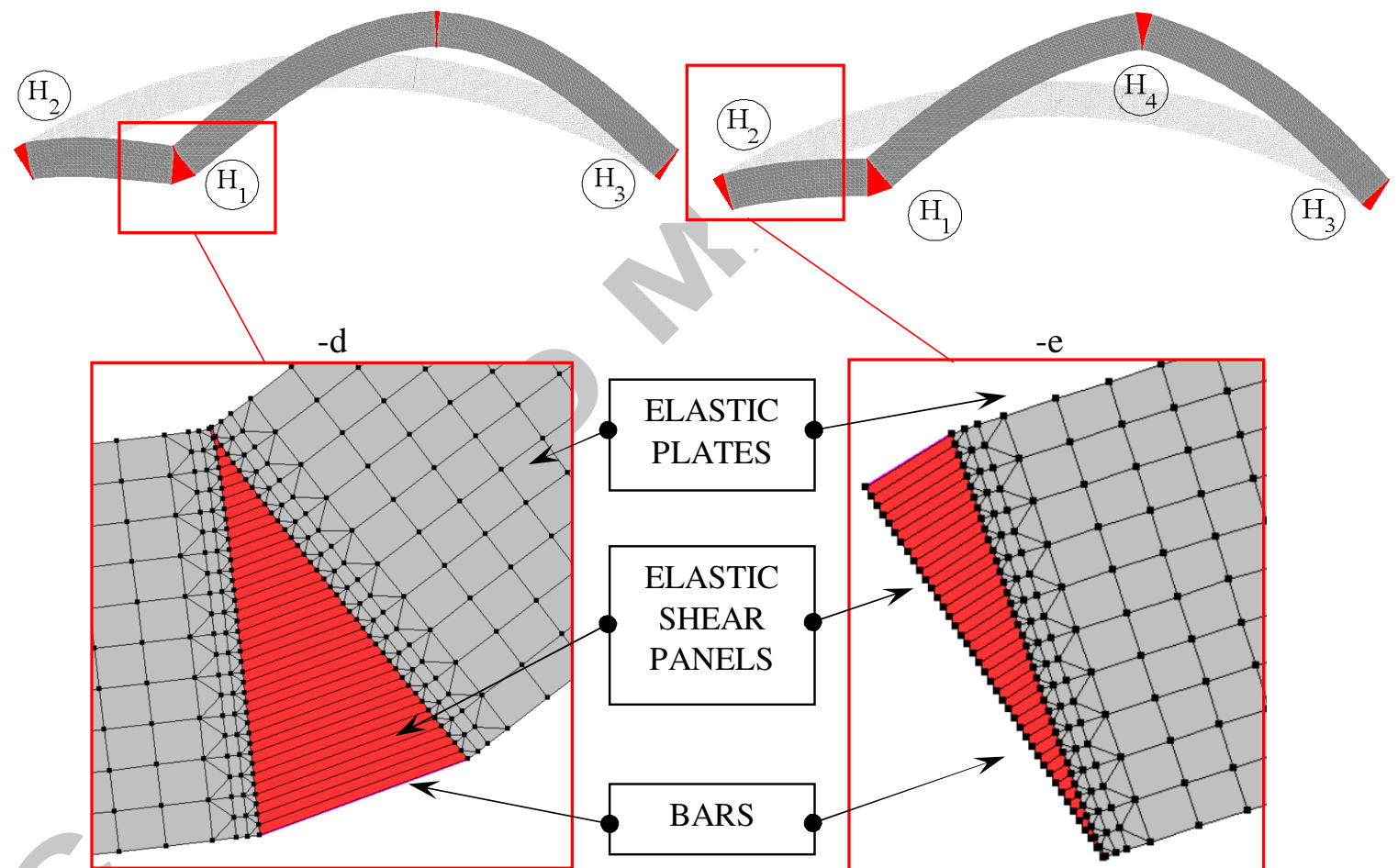

Figure 11: Unreinforced arch U_A. -a: FE discretization and LVDTs position. From - b to -e, sequence of formation of the hinges.

\subsection{Unreinforced barrel vault U_V}

The same sensitivity analyses are repeated here for the unreinforced tile barrel vault U_V. The resultant lines of thrust at different values of masonry tensile strength, with an indication of the hinges, the lower and upper bounds for the thrust lines and the collapse loads are summarized in Figure 12 from $-\mathrm{a}$ to $-\mathrm{h}$. Even more clearly than in the previous case (a consequence of the very limited thickness of the vault), the variability of the collapse load is extremely high, with a ratio of about 3.5 on collapse loads ( $919 \mathrm{~N}$ vs $261 \mathrm{~N}$ ) passing from a masonry tensile strength equal to 0.1 $\mathrm{MPa}$ to a quasi no tension material $(0.001 \mathrm{MPa})$. Thrust-line, position of the hinges and active 
failure mechanism in case of no-tension material, are shown in Figure 13, where results are again compared with those obtained with a refined 2D elasto-plastic FE discretization. Sensitivity analyses depicting collapse loads obtained varying either masonry tensile strength (subfigure $-\mathrm{a}$ ) or both tensile and compressive strength (subfigure -b) are reported in Figure 14. In this case the best fitting of the experimental collapse load is obtained for a tensile strength equal to about $0.02 \mathrm{MPa}$, see Figure 14-a. It is also interesting to point out that, apart from the extremely low load carrying capacity of such vault in presence of low strength mortar joints, the underestimation of a Heyman's approach is around 30\%, highlighting once again that sometimes the NTM hypothesis, whilst always on the safe side, can provide results affected by a scatter outside the common range of acceptability. As in the previous case, the position of the hinges does not change increasing $f_{t}$. Comparing for instance Figure 12-b and Figure 12-h, it can be noted that the position of the hinges is exactly the same, two at the abutments, one under the concentrated load and the other at $97^{\circ}$ from the left abutment. In analogy with computations done for the unreinforced arch, some elasto-plastic analyses with Strand7 are carried out, assuming again the arch elastic with concentrated plasticity on hinges found with limit analysis. The results obtained, compared with experimental loaddisplacement curves in Figure 15-a, show once again that the utilization of FE codes with concentrated plasticity in combination with limit analysis can provide pretty good results, predictive of initial stiffness, ductility and load carrying capacity. The sequence of hinges formation is finally shown in Figure 15-b and Figure 16. The knowledge of the exact sequence of formation is paramount when a strengthening intervention on an already damaged arch (e.g. for a seismic upgrading) must be carried out. 


\section{ACCEPTED MANUSCRIPT}

Revised version, modifications highlighted in color YELLOW

$f_{t}=0.001 \mathrm{MPa}$
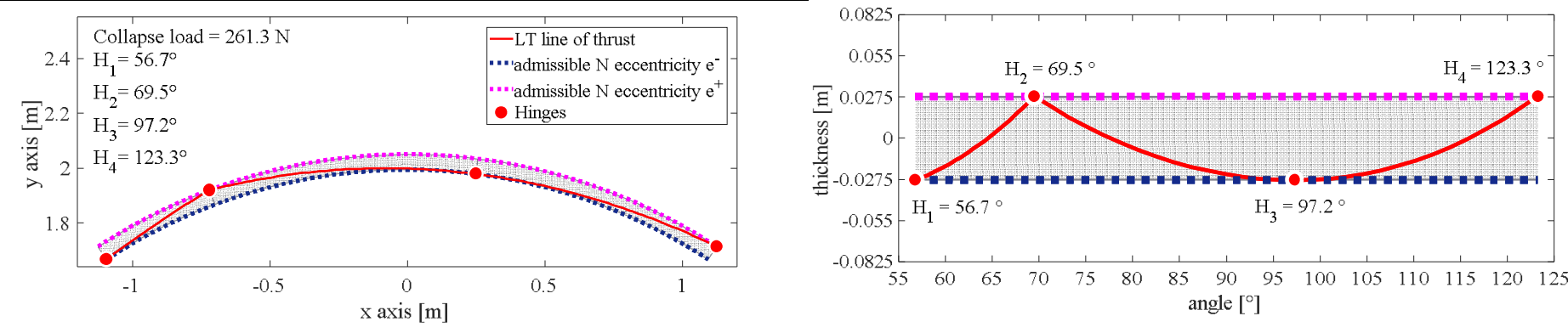

$-a$

$-b$
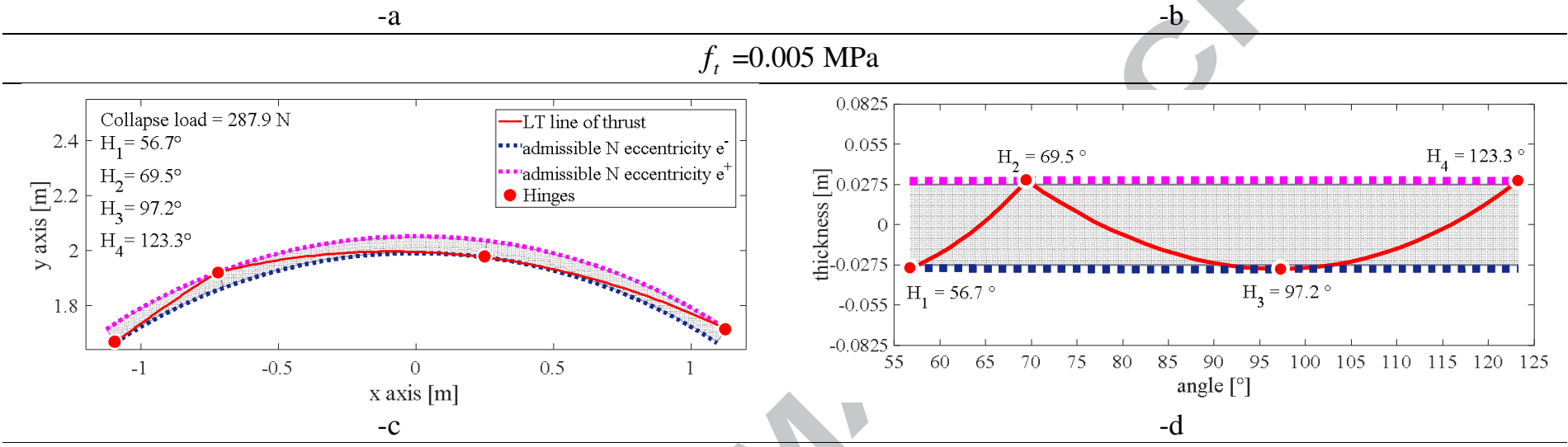

$f_{t}=0.05 \mathrm{MPa}$
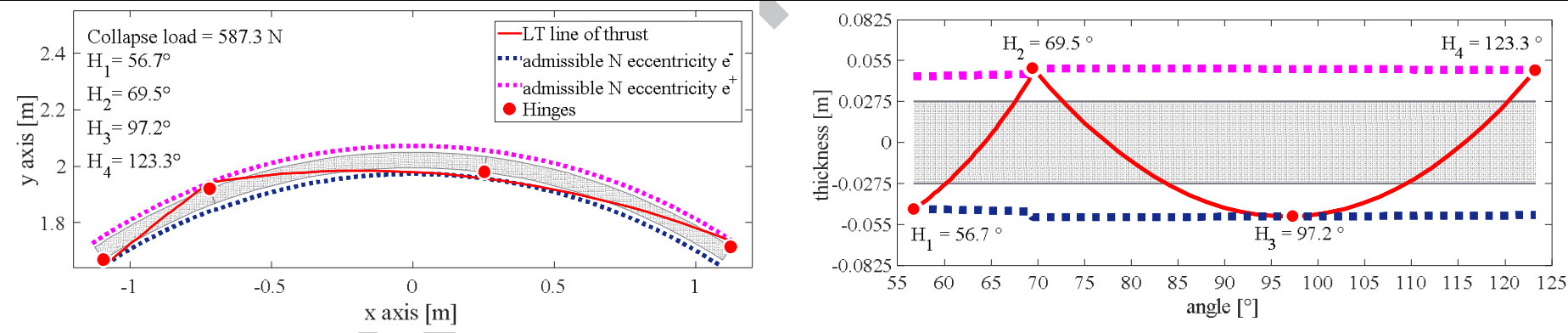

$-\mathrm{e}$

$-\mathrm{f}$

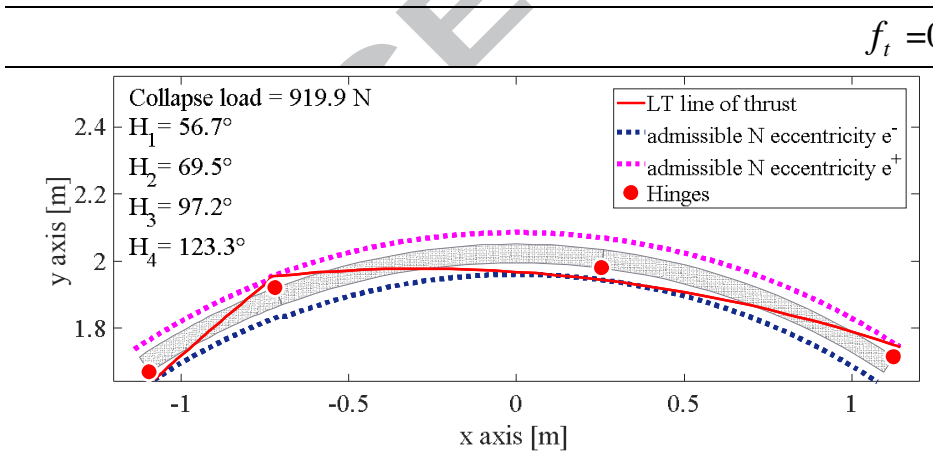

$-\mathrm{g}$

Figure 12: Unreinforced vault $U_{-}$V. $-\mathrm{a},-\mathrm{c},-\mathrm{e},-\mathrm{g}$ : lines of thrust at different vaules of masonry tensile strength. -b, $\mathrm{d},-\mathrm{f},-\mathrm{h}$ : identification of hinges position as a function of angle $180^{\circ}-\alpha$. 


\section{ACCEPTED MANUSCRIPT}

Revised version, modifications highlighted in color YELLOW

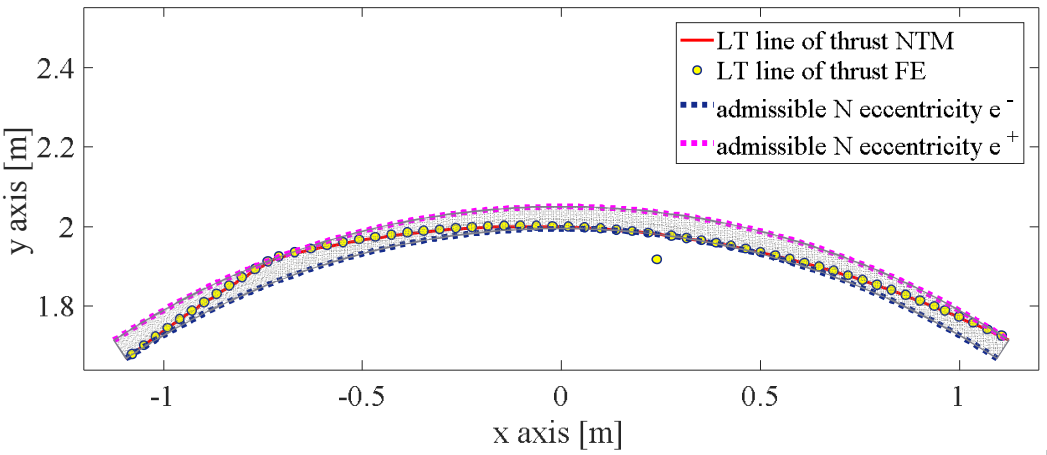

NTM
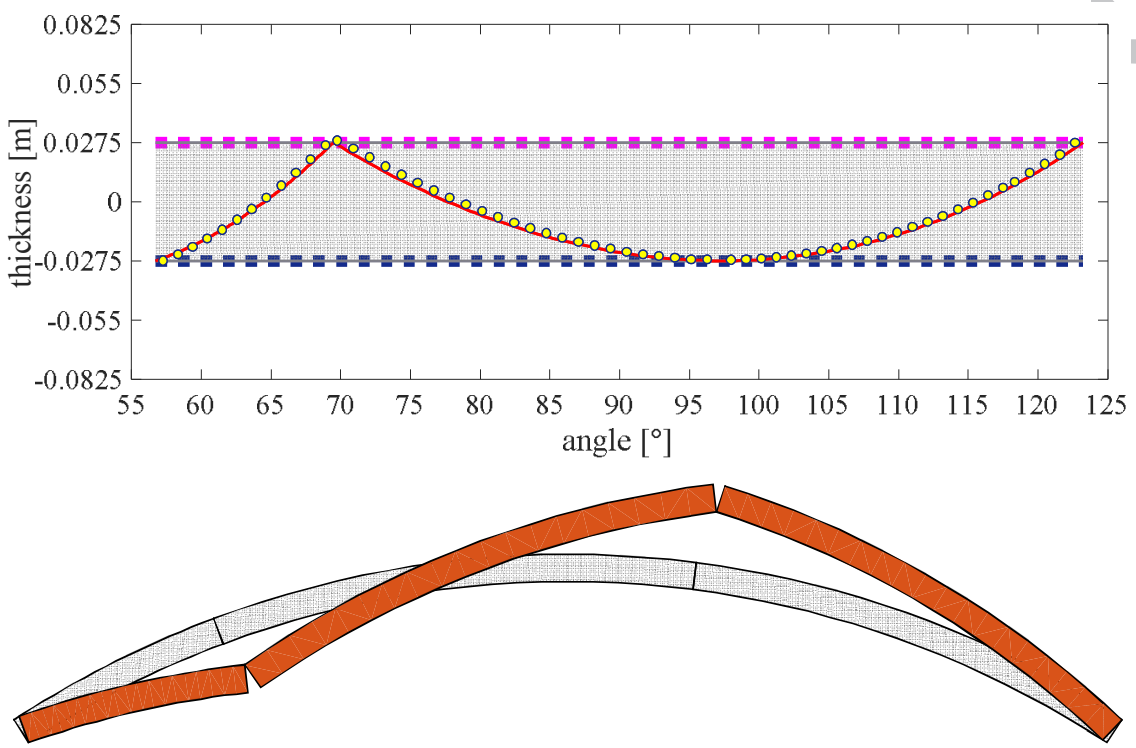

Figure 13: Unreinforced vault $\mathrm{U}_{\triangle} \mathrm{V}$ in case of no-tension material. -a: line of thrust at different vaules of masonry tensile strength. $-\mathrm{b}$ : identification of hinges position as a function of angle $180^{\circ}$ $\alpha$. - c: corresponding failure mechanism.

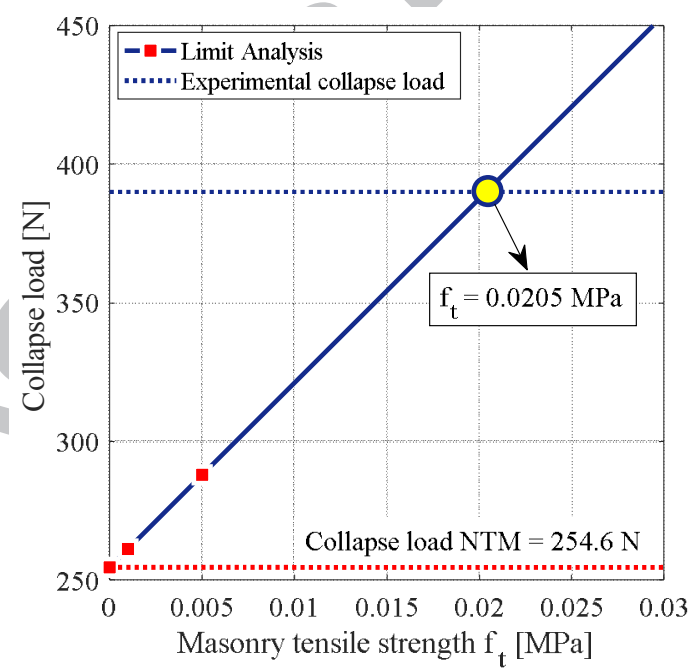

-a

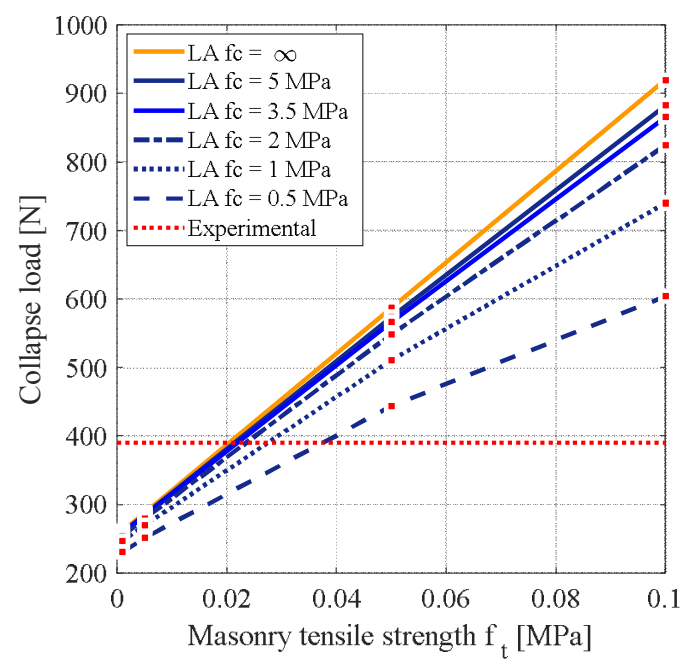

$-b$

Figure 14: Unreinforced vault U_V: sensitivity analyses on the collapse load changing masonry tensile strength. -a: infinite compressive strength. -b: finite compressive strength. 


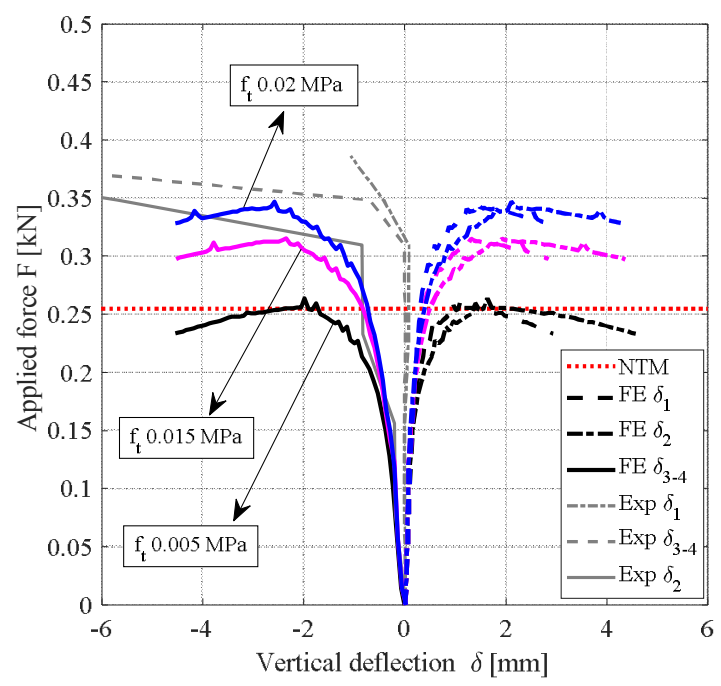

-a

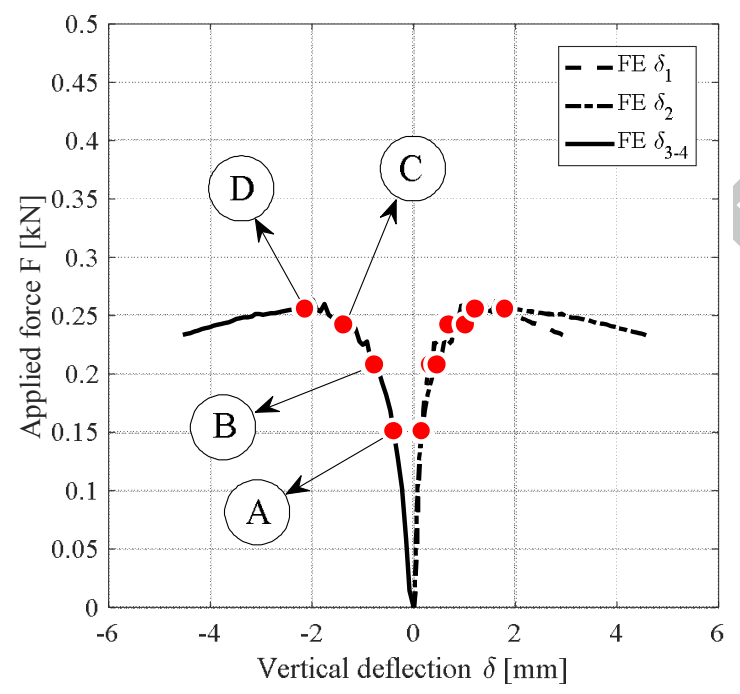

$-b$

Figure 15: Unreinforced vault U_V. -a: utilization of an elasto plastic FE approach with plastic hinges located on positions found by LA. -a: comparison with experimental data. -b: sequence of formation of the hinges. 


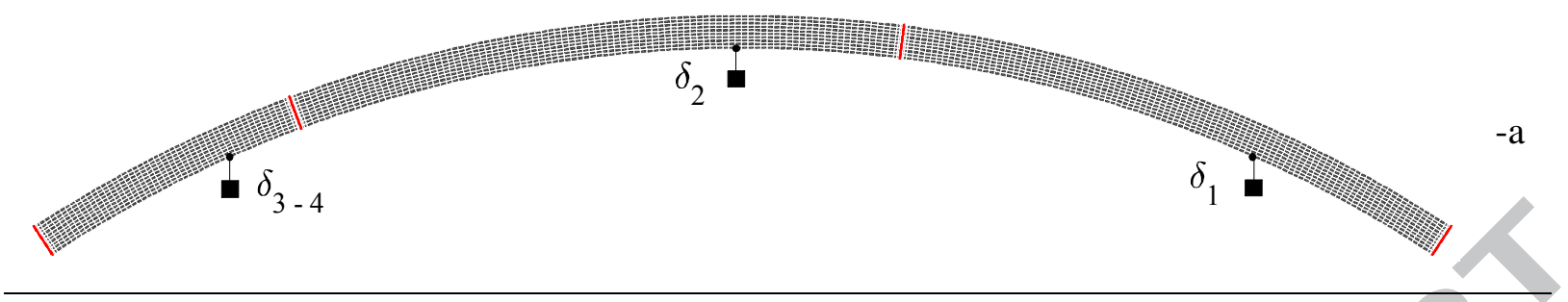

A

Scale factor: 200

B

Scale factor: 200
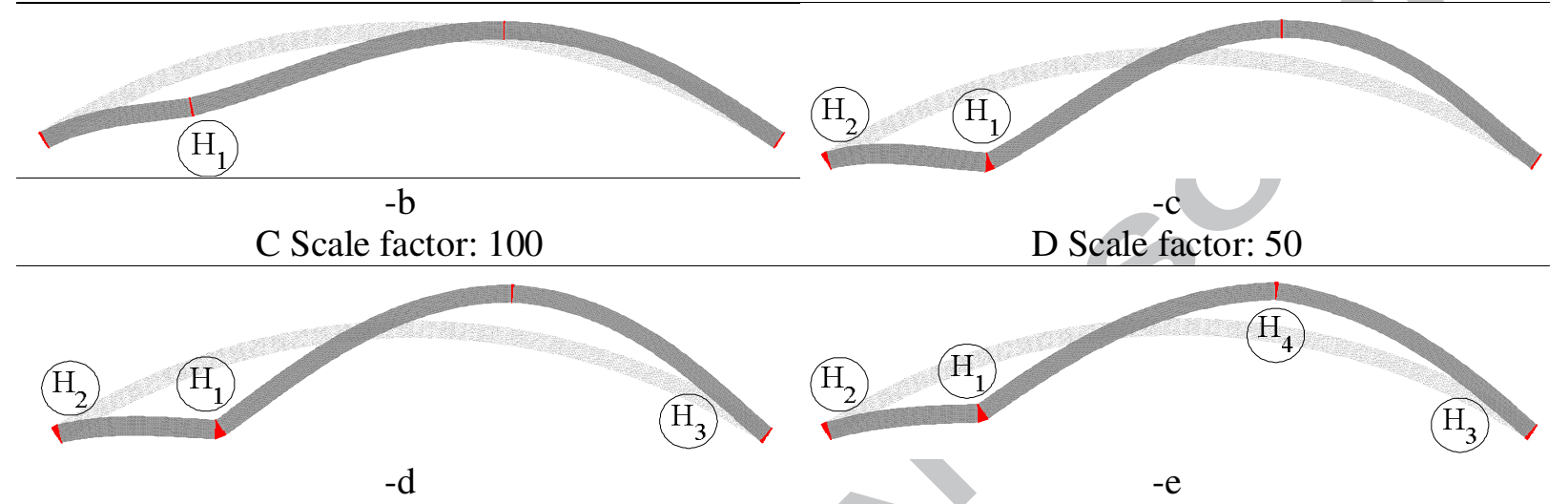

Figure 16: Unreinforced vault U_V. -a: FE discretization and identification of the LVDTs position. From $-b$ to $-\mathrm{e}$ : sequence of hinges formation.

\subsection{SRG reinforced arch (SRG_A)}

Among the possible different choices of masonry tensile strength to adopt, in absence of a comprehensive characterization of the materials available, we assume a tensile strength for masonry $f_{t}$ equal to about $0.077 \mathrm{MPa}$, which - as already discussed- allows to optimally fit the collapse load in the unreinforced case. With such value a priori fixed, it is possible to repeat some sensitivity analyses in the reinforced case varying $\sigma_{\text {reinf }}$, the ultimate equivalent tensile strength of the reinforcement. The ultimate tensile force per meter to assign to trusses representing the reinforcement is therefore $F_{\text {rein }}=d_{a} \sigma_{\text {reinf }}$, where $d_{a}$ is the depth of the arch. The numerical value of $\sigma_{\text {reinf }}$ which minimizes the difference between experimental and numerical collapse loads can be then compared with previous experimental characterization on the bond behavior, if any, or with simplified formulas provided by codes of practice.

For SRG_A, the resultant lines of thrust at different values of $F_{\text {rein }}$, with an indication of the hinges, the lower and upper bounds for the thrust lines and the collapse loads are summarized in Figure 17 from $-\mathrm{a}$ to $-\mathrm{h}$. As it is possible to notice, the lower bound line of thrust shifts progressively downwards (blue thick dotted line) and for a $\sigma_{\text {reinf }}=\sigma_{r}=172 \mathrm{MPa}$ the experimental collapse load is approximated in an optimal way, see Figure 18-a, assuming also $f_{c} \rightarrow \infty$. The experimental range of $\sigma_{\text {reinf }}$, with indication of $\sigma_{\mathrm{T} 1}, \sigma_{\mathrm{u}}$ and the debonding strength envelope are also indicated. As discussed in the companying paper [1], where the reader is referred to further details, $\sigma_{\mathrm{T} 1}$ indicates the stress when debonding between masonry and reinforcement occurs, whereas $\sigma_{u}$ refers to reinforcement tensile failure. Such values are assumed according to specific literature in the field, as explained in [1]. The same sensitivity analyses are carried out assuming different values of masonry 
compressive strength and the results are depicted in Figure 18-b, obtaining a similar trend, but with a better experimental values fitting. Clearly, assuming an infinite masonry compressive strength, an overestimation of the load carrying capacity is obtained, even assuming for trusses an ultimate strength equal to $\sigma_{\mathrm{T} 1}$ (which seems the most realistic mode of failure for the reinforcement according to experimental evidences). The agreement is improved when a low compressive strength is assumed, i.e. in case of masonry crushing, see Figure 18-b, which is usually observed in case of reinforced arches, but an optimal match is obtained only with unrealistic small values of compressive strength. Apart issues related to the limited compressive strength, such an outcome can be justified remembering that Heyman's assumptions exclude sliding between blocks, with failure due to the formation of a four-hinges mechanism (see Figure 19, where it is also visible that the position of the hinges remains in practice unaltered with respect to the unreinforced case). Such model, which indeed does not allow to eventually reproduce shear failures of the masonry material, is quite limited for the reinforced cases, where a mode I detachment with sliding at the springing is not reproducible. For this reason, in Figure 20 simulations are repeated with a possible shear sliding of the interfaces, assuming different values of the friction angle $\Phi$ and a cohesion almost vanishing (equal to $f_{t}$ ). Figure $20-\mathrm{a}$ and $-\mathrm{b}$ show the collapse loads so obtained varying $\Phi$ and $\sigma_{\text {reinf }}$, whereas Figure 20-c depicts some meaningful collapse mechanisms obtained in the simulations. As it can be observed, for low/medium friction angles, an increase of $\sigma_{\text {reinf }}$ results in an activation of a sliding failure, mainly concentrated on abutments or under the point load. The activation of sliding is also visible from the trend of the collapse load, which reaches a plateau at progressively increased values of $\sigma_{\text {reinf }}$. This means that failure is totally independent from the reinforcement strength, i.e. collapse mechanism does not involve reinforcement trusses rupture.

Assuming shear sliding, a perfect agreement with experimental data is obtained, with friction angles between 20 and $22.5^{\circ}$. 
Revised version, modifications highlighted in color YELLOW

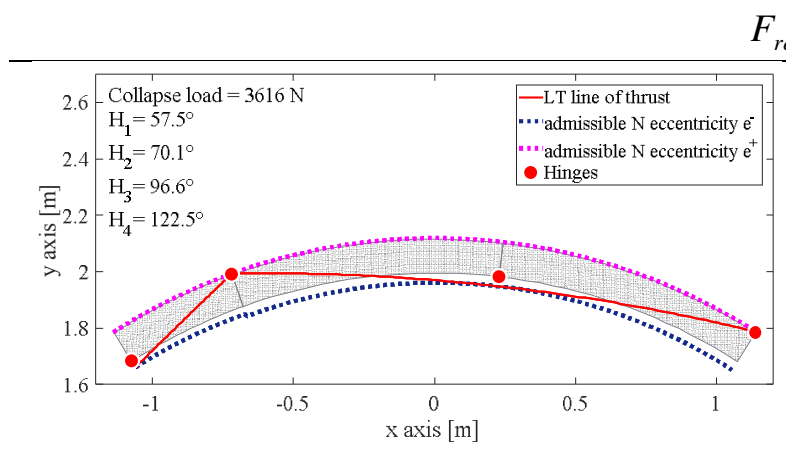

$F_{\text {rein }}=4 \mathrm{kN} / \mathrm{m}$

$-\mathrm{a}$

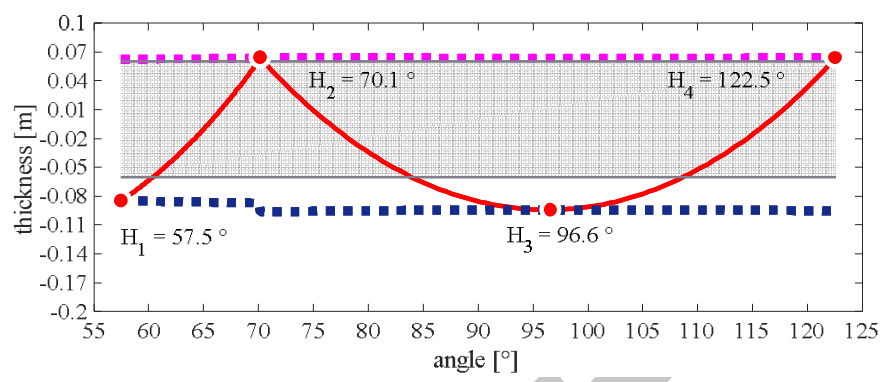

$-b$

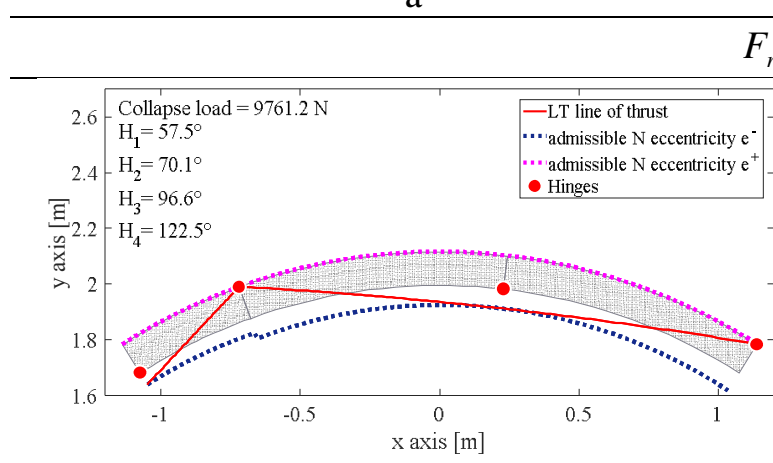

$-\mathrm{c}$

$$
F_{\text {rein }}=20 \mathrm{kN} / \mathrm{m}
$$

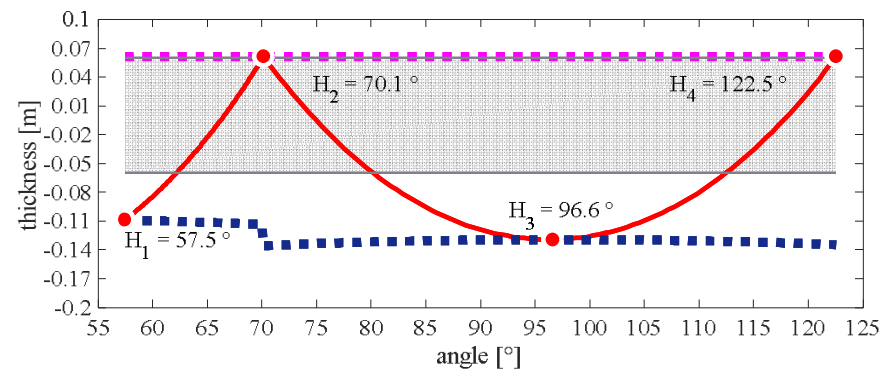

$-d$

\section{$F_{\text {rein }}=28 \mathrm{kN} / \mathrm{m}$}
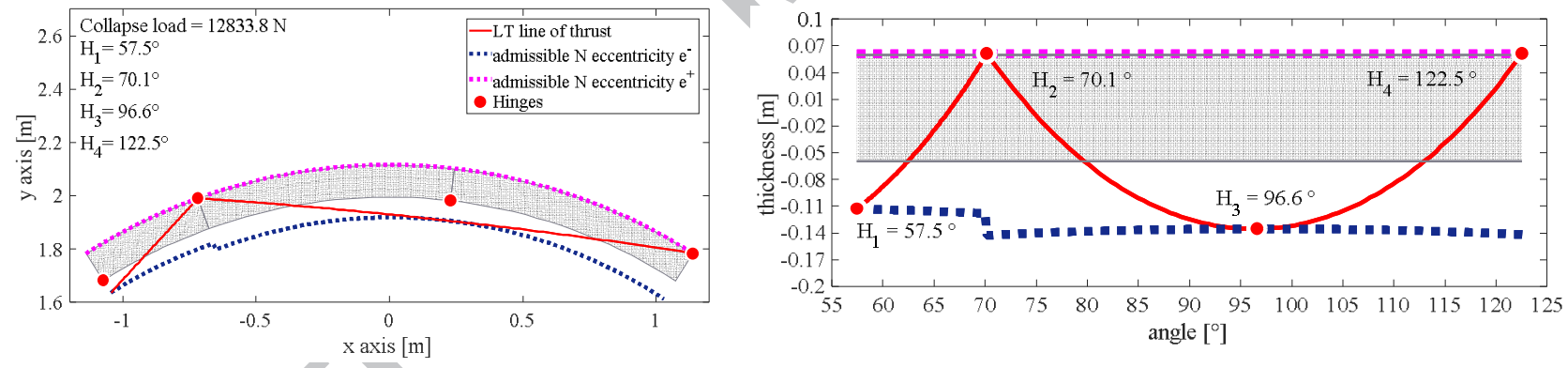

$-\mathrm{e}$

$-\mathrm{f}$

$$
F_{\text {rein }}=60 \mathrm{kN} / \mathrm{m}
$$

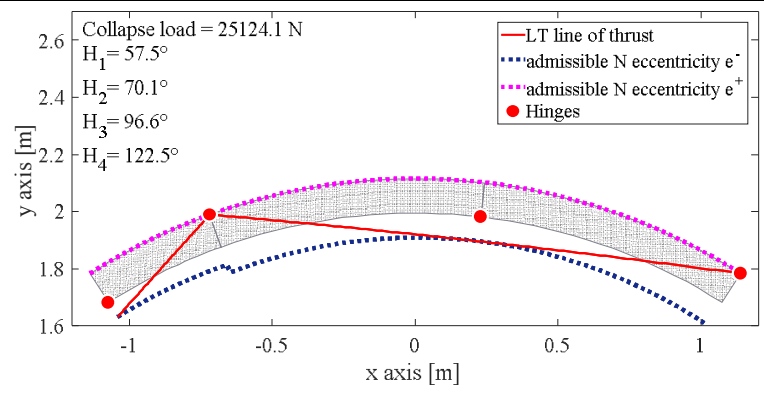

$-\mathrm{g}$

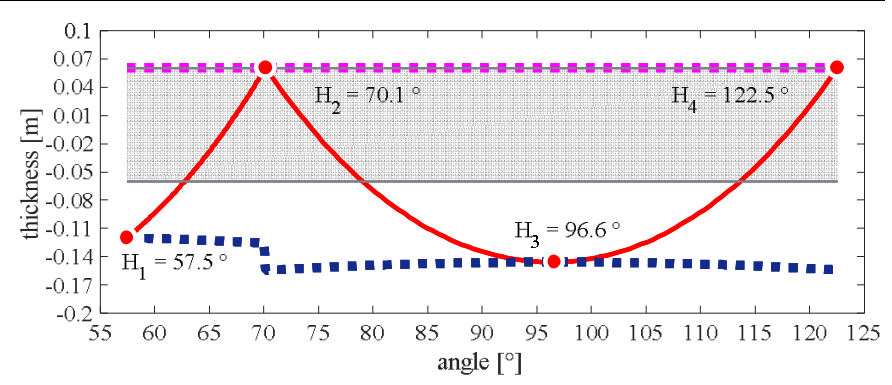

$-\mathrm{h}$

Figure 17: Reinforced arch SRG_A. $-\mathrm{a},-\mathrm{c},-\mathrm{e},-\mathrm{g}$ : lines of thrust at different vaules of reinforcement ultimate force $F_{\text {rein }} .-\mathrm{b},-\mathrm{d},-\mathrm{f},-\mathrm{h}$ : identification of hinges position as a function of angle $180^{\circ}-\alpha$. 


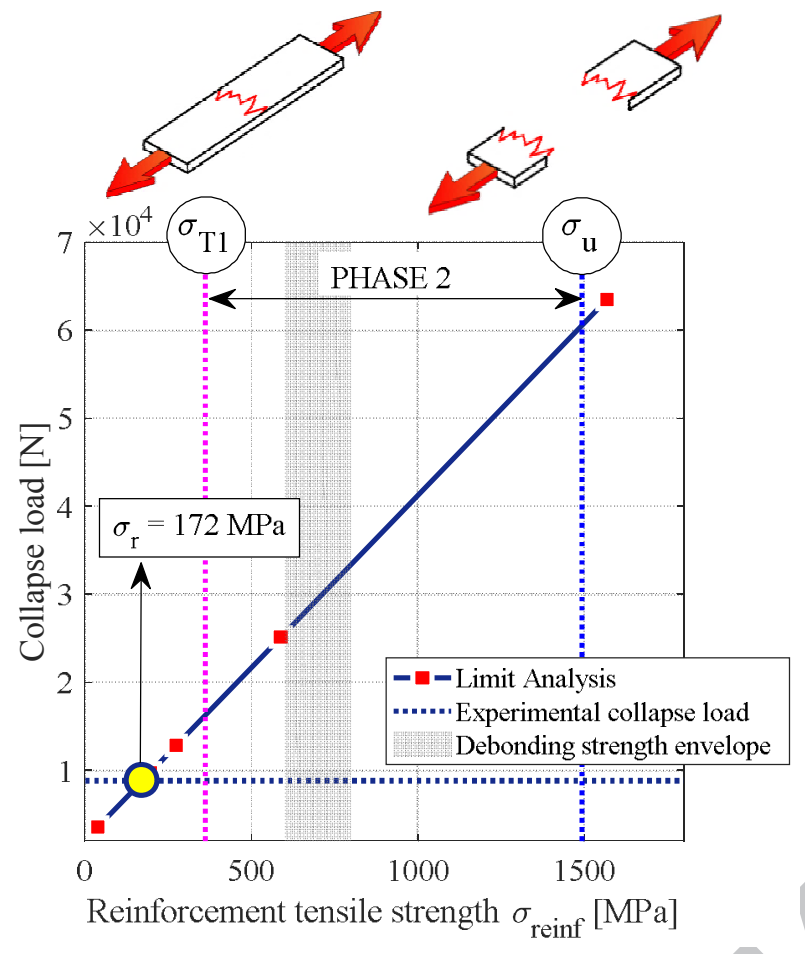

$-a$

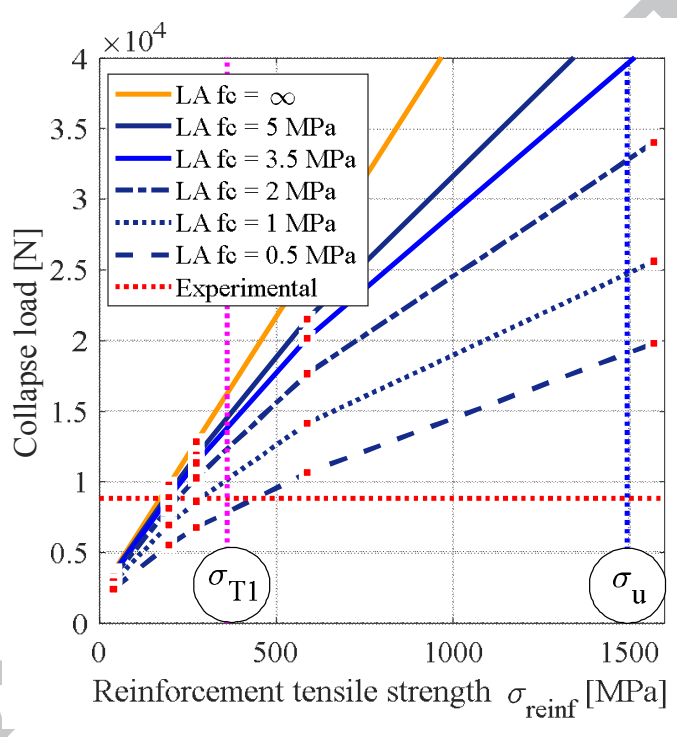

$-b$

Figure 18: Reinforced arch SRG_A, sensitivity analyses on the collapse load changing $\sigma_{\text {reinf }}$.a: infinite compressive strength, $-\mathrm{b}$ : finite compressive strength.

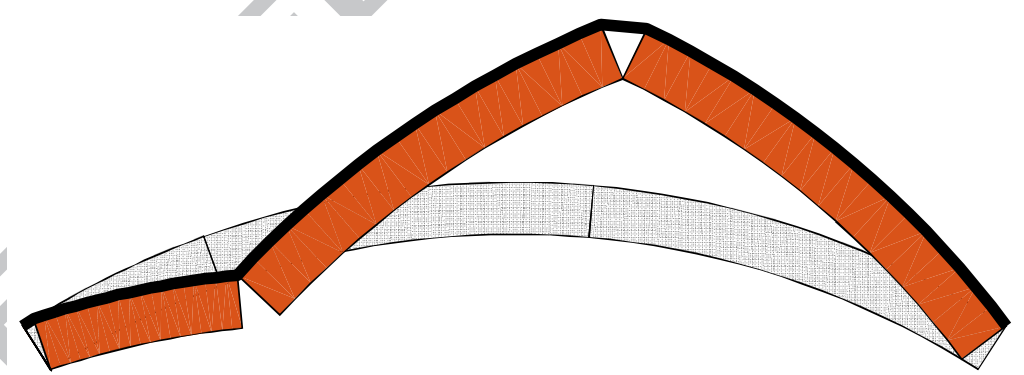

Figure 19: Reinforced arch SRG_A: deformed shape at collapse obtained with the LB LA code. 


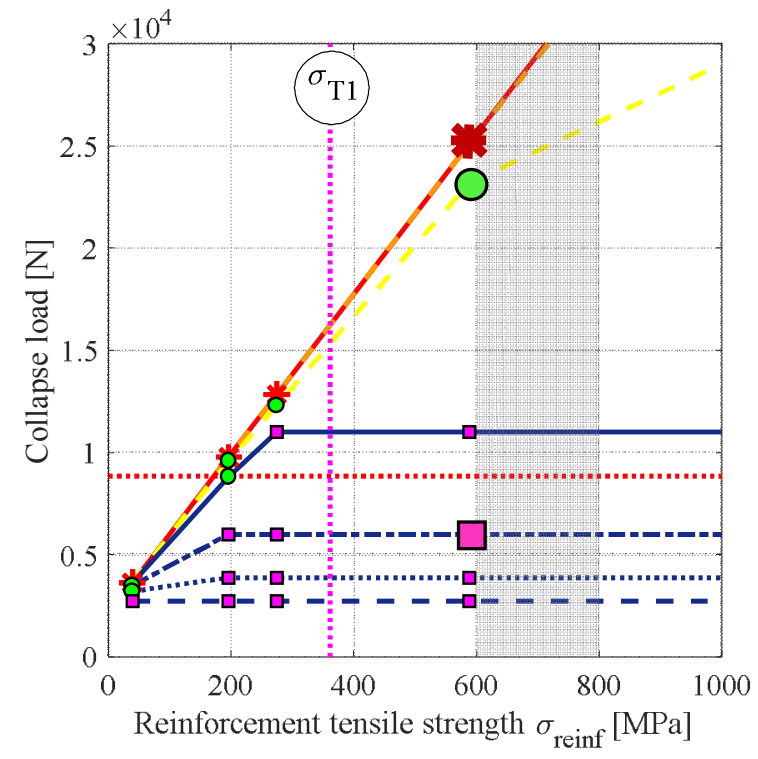

$-\mathrm{a}$

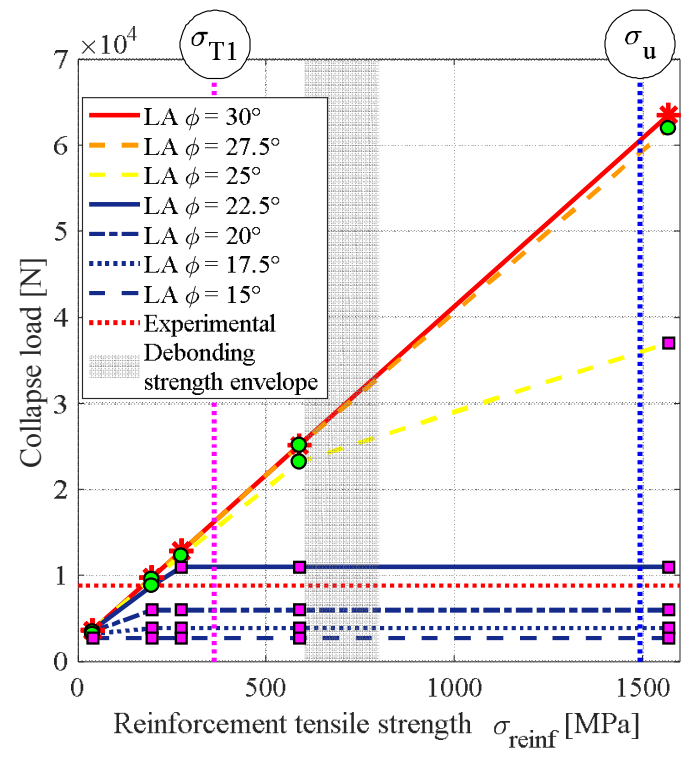

$-\mathrm{b}$

formation of four hinges

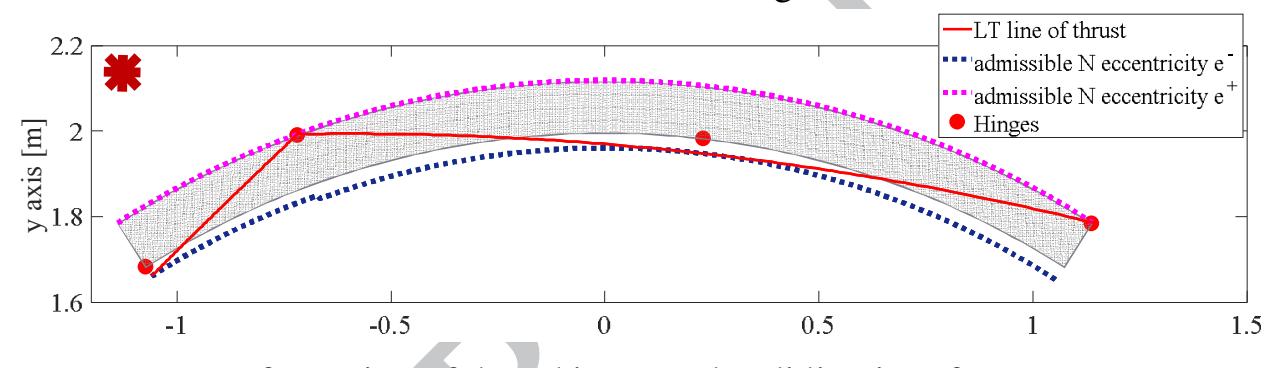

formation of three hinges and a sliding interface

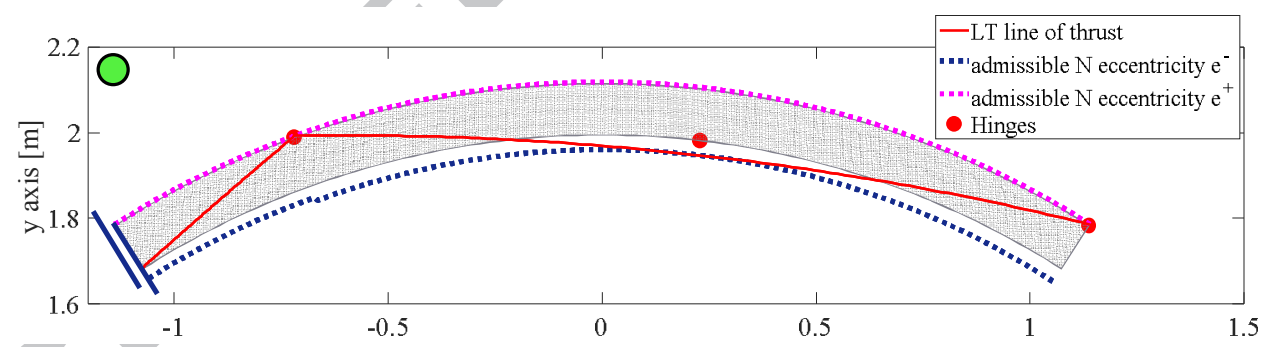

formation of one hinge and three sliding interfaces

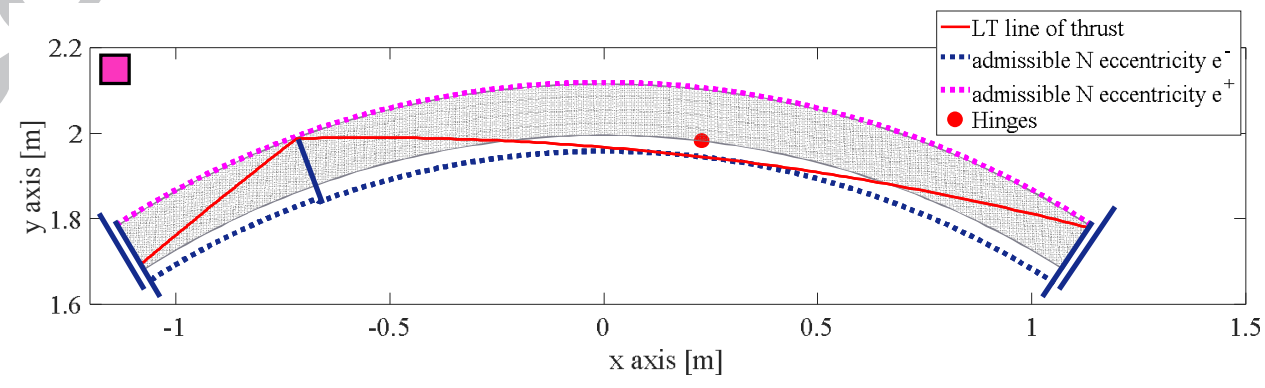

$-\mathrm{c}$

Figure 20: Reinforced arch SRG_A, sensitivity analyses on the collapse load changing $\sigma_{\text {reinf }}$ assuming infinite compressive strength. $-\mathrm{a}$ and $-\mathrm{b}$ : collapse loads (-a detail at small $\sigma_{\text {reinf }}$ ). -c indication of the failure mechanisms active in some meaningful cases. 


\subsection{FRP and TRM reinforced barrel vaults (FRP_V and TRM_V)}

In analogy to what was done for the reinforced arch, a sensitivity analysis is carried out on the FRP and TRM reinforced barrel vaults (FRP_V and TRM_V), again varying in a wide range the value of the conventional ultimate strength of the reinforcement $\sigma_{\text {reinf }}$. In the numerical model, there is obviously no distinction between the different typologies of failures occurring as a consequence of the different reinforcing system, therefore sensitivity analysis results reported in Figure 21 hold for both the FRP_V and TRM_V case. As can be seen, in analogy with the case discussed for arches, the lower bound for the thrust lines progressively shifts downward at increasing values of reinforcement conventional tensile strength. Values of $\sigma_{\text {reinf }}=\sigma_{\mathrm{r}}$ that make the LA model fitting in an optimal way the collapse loads found experimentally are sketched in Figure 22-a (FRP_V) and Figure 22-c, along with a sensitivity analysis on collapse loads obtained varying $\sigma_{\text {reinf }}$. For FRP, Figure 22-a, the debonding strength evaluated according to CNR DT-200 [41] is also indicated with a vertical dotted line. For TRM, Figure 22-c, the expected experimental range for $\sigma_{\text {reinf }}$, with indication of $\sigma_{\mathrm{T} 1}, \sigma_{\mathrm{u}}$ and the debonding strength envelope are also indicated for the sake of comparison. $\sigma_{\mathrm{r}}$ turns out to be equal to 187 and $386 \mathrm{MPa}$ for FRP and TRM reinforcing systems, respectively. Whilst the numerical prediction for TRM appears very satisfactory, with almost perfect match for $\sigma_{\text {reinf }}=\sigma_{\text {T1 }}$, FRP vault seems to experimentally collapse far before that CNR DT200 [41] debonding strength is reached. In order to investigate if the reason is linked to masonry crushing, sensitivity analyses are repeated at progressively decreased values of compressive strength and results are shown in Figure 22-b and Figure 22-d for FRP and TRM respectively. As expected, collapse load slightly decreases, but from the results obtained, it appears clear that to take into account masonry crushing does not change the situation drastically. As a consequence, FRP case still exhibits quite large deviations, whereas TRM matches even better experimentation. Again the collapse mechanism is ruled by the formation of four plastic hinges, Figure 23, in the same positions found for the unreinforced case.

It is interesting also to notice that the lowest $\sigma_{r}$ numerically found among the three tested strengthening systems is the FRP one, meaning that failure occurs unexpectedly much more prematurely than in the other two cases. A possible cause can be therefore, in analogy with the arch, a shear sliding, again typically observed at springing. Simulations are therefore repeated with limited shear strength, assuming again different values for the friction angle $\Phi$ and a cohesion almost vanishing (equal to $f_{t}$ ). Results of the sensitivity analysis in terms of obtained collapse loads are summarized in Figure 20 (subfigure -a refers to FRP and -b to TRM). In agreement with arch results, experimental collapse load is reproduced quite well assuming CNR DT-200 [41] debonding strength for FRP and $\sigma_{\text {reinf }}=\sigma_{\mathrm{T} 1}$ for TRM, accounting for possible sliding with friction angle of the interfaces ranging between 17.5 and $20^{\circ}$. 
$F_{\text {rein }}=3.33 \mathrm{kN} / \mathrm{m}$
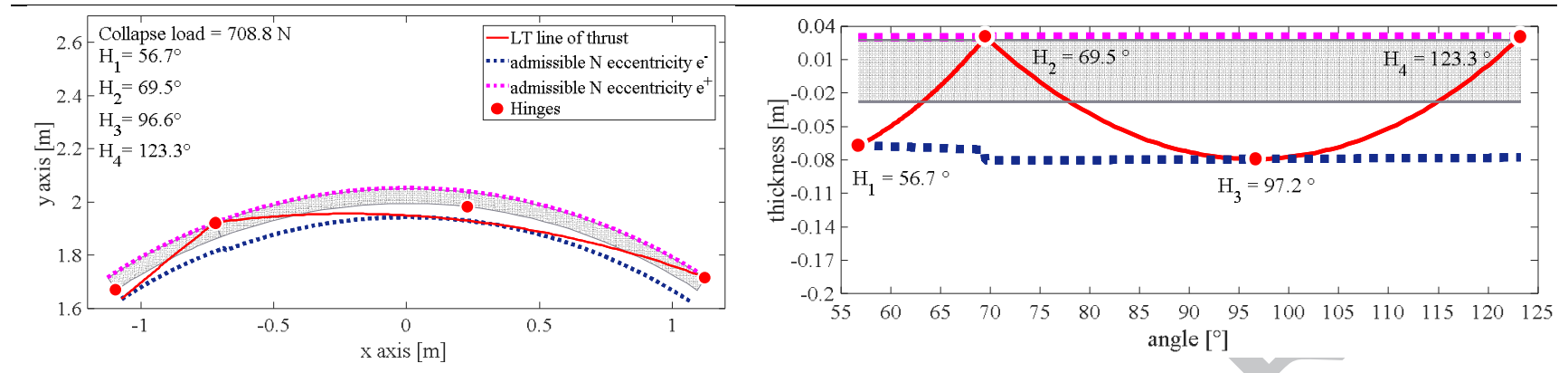

$-\mathrm{a}$

$-b$

$F_{\text {rein }}=16.6 \mathrm{kN} / \mathrm{m}$
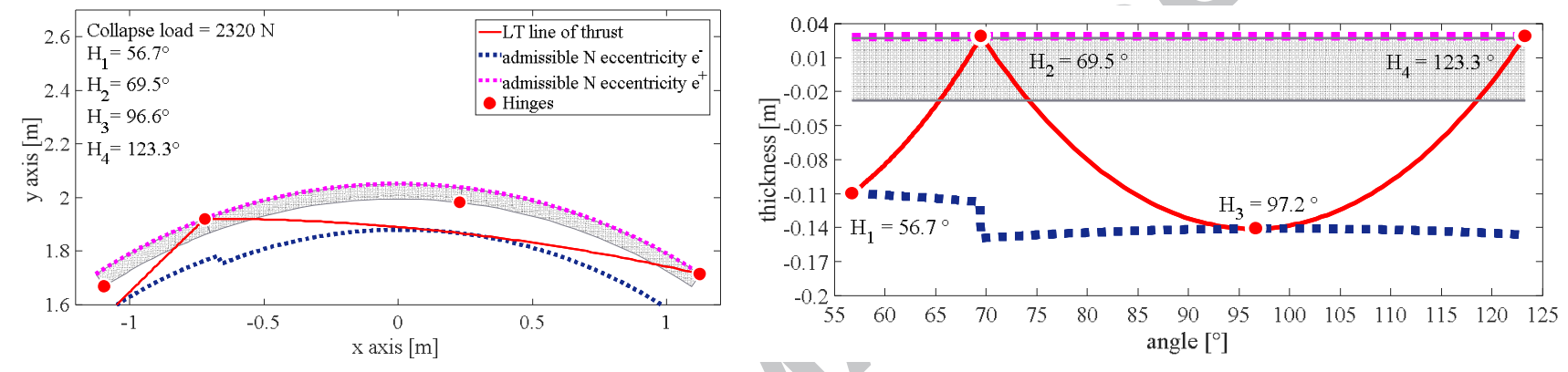

$-\mathrm{c}$

$-d$

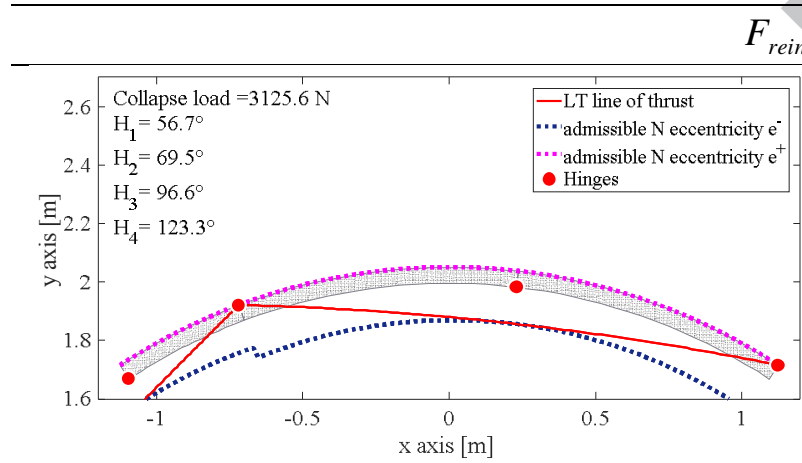

$F_{\text {rein }}=23.3 \mathrm{kN} / \mathrm{m}$
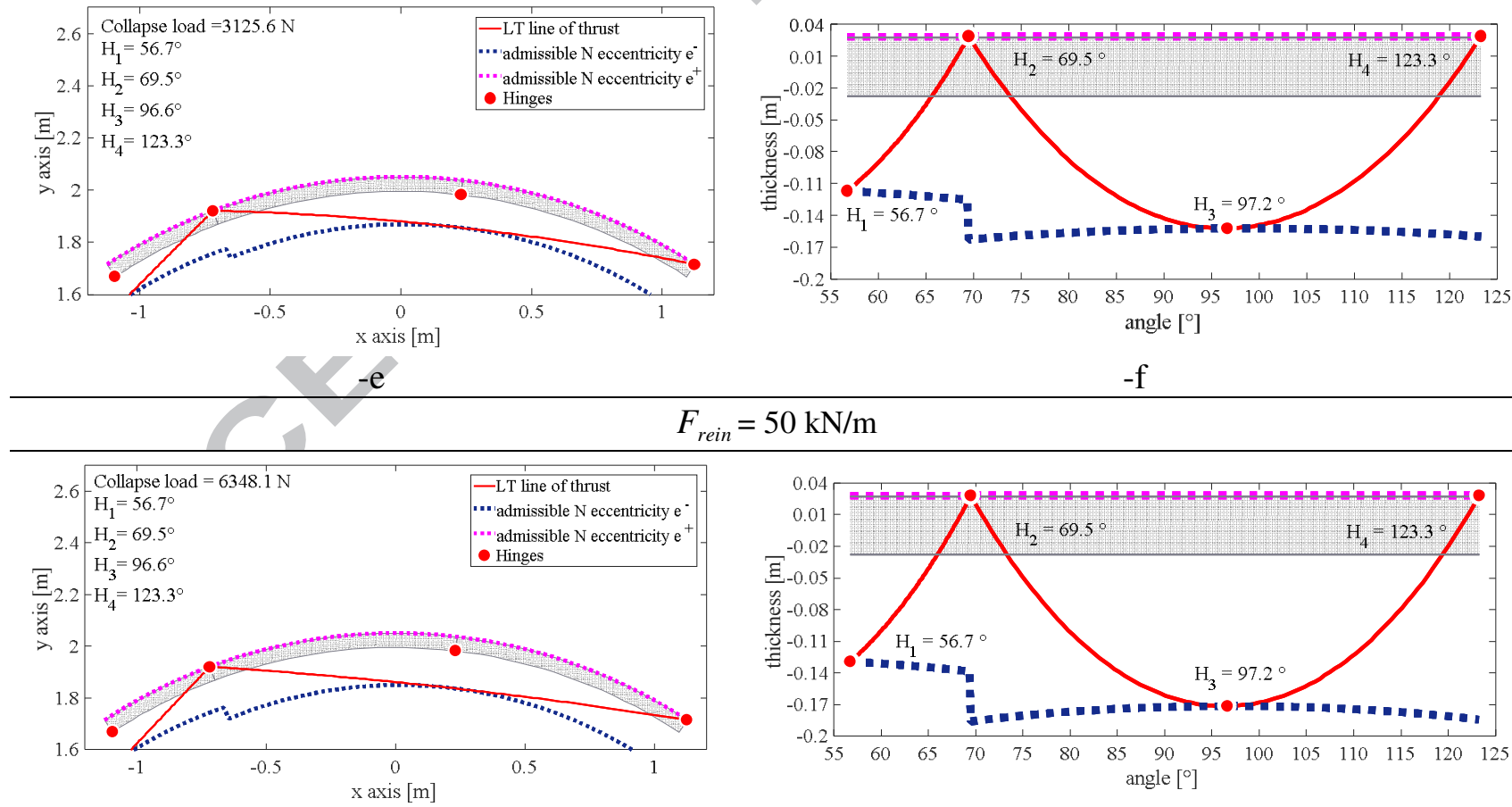

$-\mathrm{g}$

$F_{\text {rein }}=50 \mathrm{kN} / \mathrm{m}$

$-f$

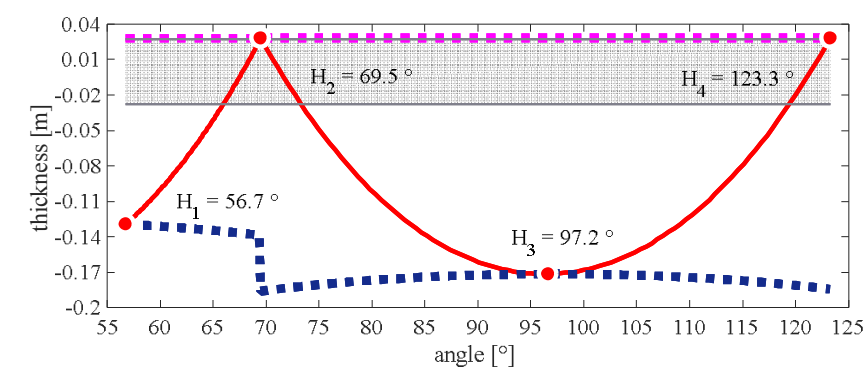

$-\mathrm{h}$

Figure 21: Reinforced barrel vaults (FRP_V and TRM_V). $-\mathrm{a},-\mathrm{c},-\mathrm{e},-\mathrm{g}$ : lines of thrust at different vaules of masonry tensile strength. $-\mathrm{b},-\mathrm{d},-\mathrm{f},-\mathrm{h}$ : identification of hinges position as a function of angle $180^{\circ}-\alpha$. 


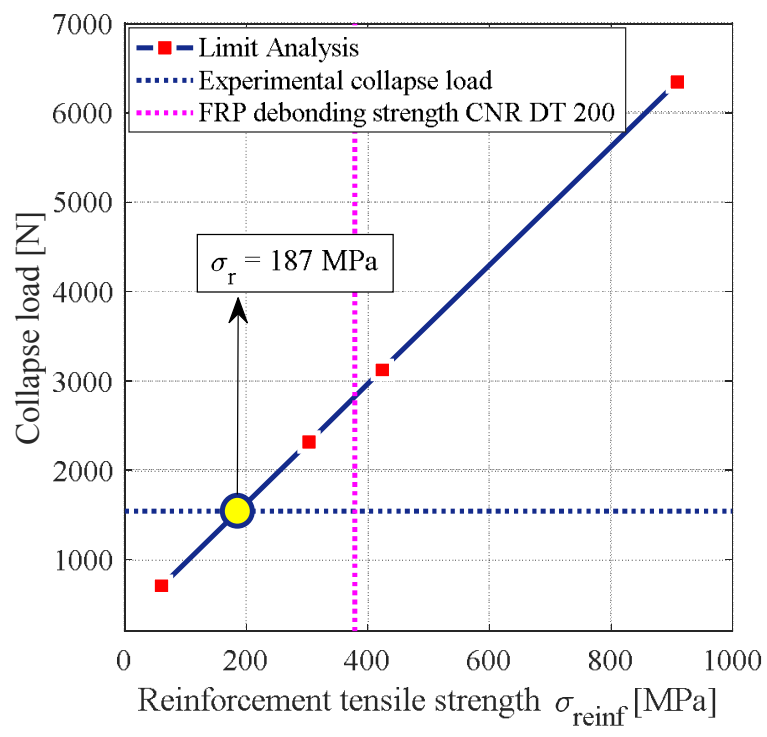

$-a$

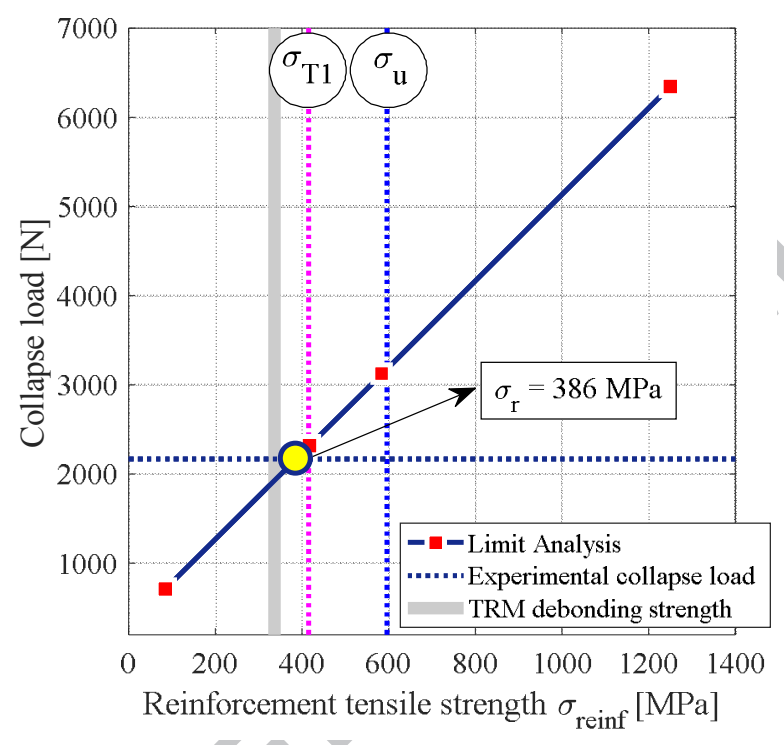

$-\mathrm{c}$

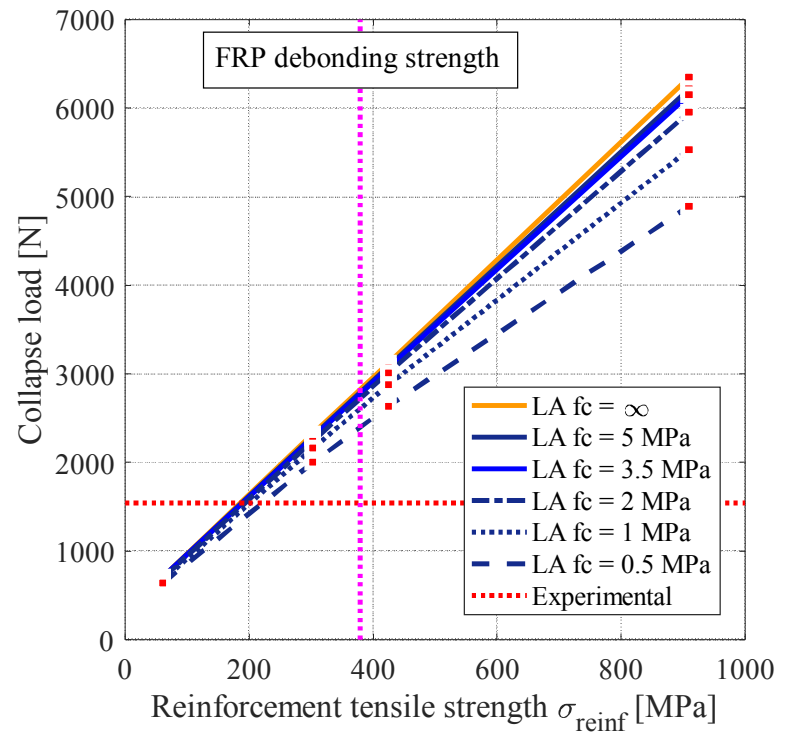

$-\mathrm{b}$

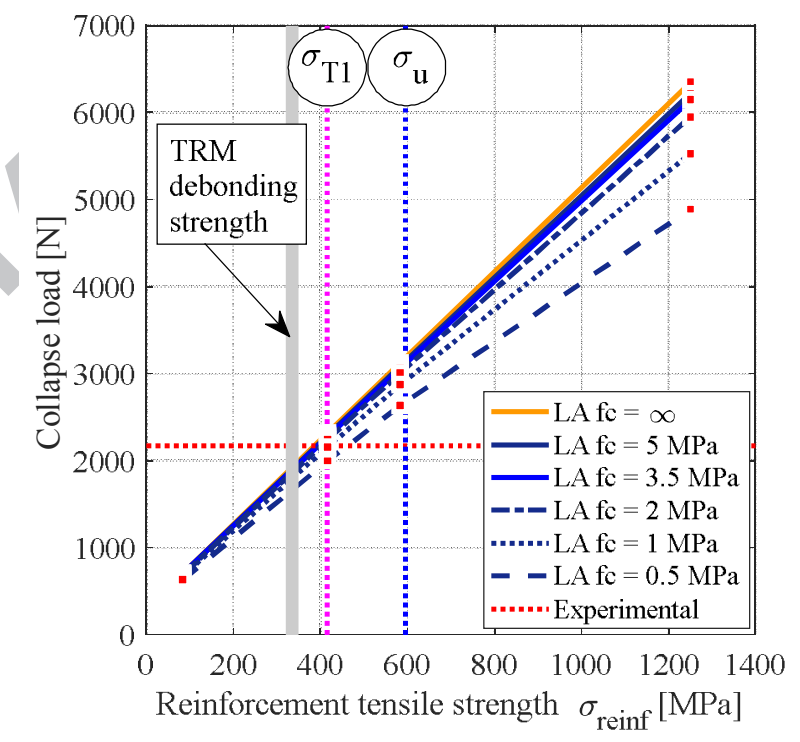

$-d$

Figure 22: Reinforced barrel vaults sensitivity analyses on the collapse load changing $\sigma_{\text {reinf }} \cdot-\mathrm{a}$ : FRP_V, infinite compressive strength, -b: FRP_V, finite compressive strength, -c: TRM_V, infinite compressive strength, $-\mathrm{d}$ : TRM_V, finite compressive strength.

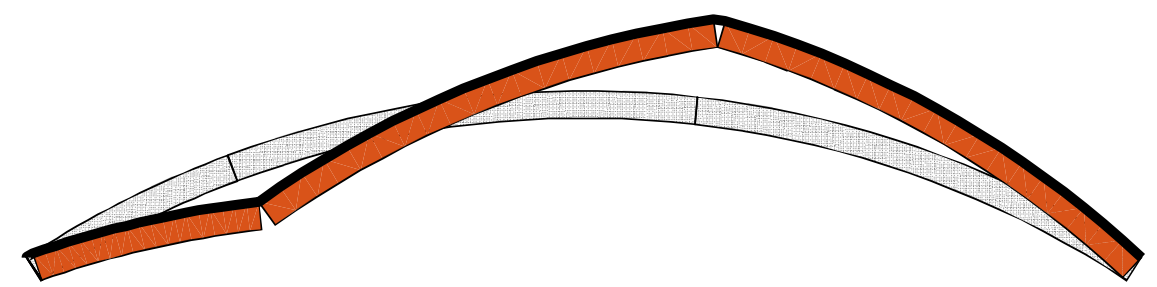

Figure 23: Reinforced barrel vaults (FRP_V and TRM_V): deformed shape at collapse obtained with the LB LA code. 

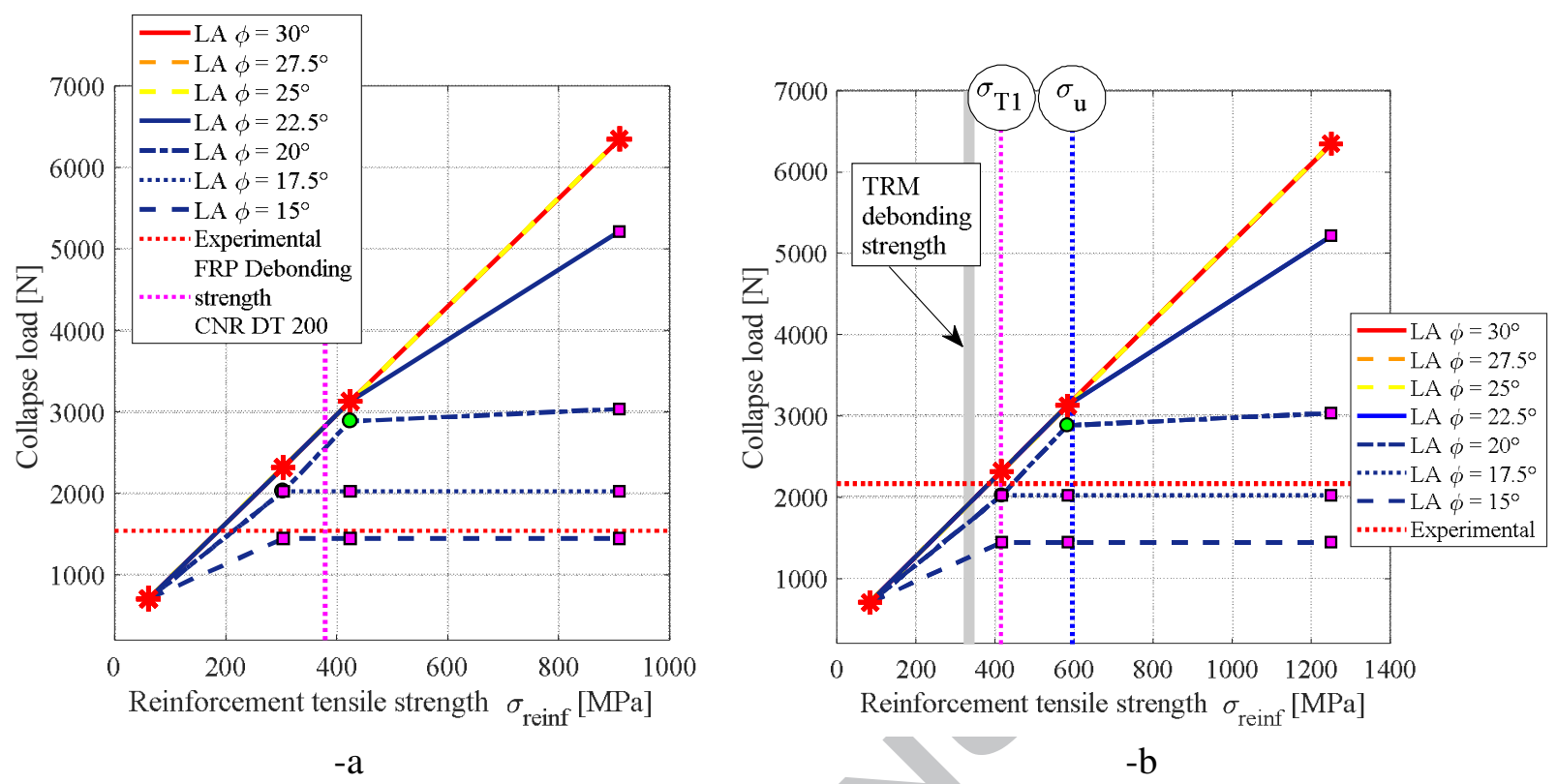

Figure 24: Reinforced barrel vault FRP_V (-a) and TRM_V (-b), sensitivity analyses on the collapse load changing $\sigma_{\text {reinf }}$ assuming infinite compressive strength and with sliding allowed.

\section{Conclusions}

After a comprehensive in-situ experimentation on two masonry arches and three tile barrel vaults reinforced in various ways and with different materials, the present paper has presented a simple lower bound FE limit analysis code which accounts for masonry a possible finite tensile and compressive strength as well as shear failure, ruled by a Mohr-Coulomb law.

From a final analysis of the numerical results obtained by means of comprehensive sensitivity analyses properly discussed in the paper, the following considerations can be drawn:

1) For the unreinforced case, a deeper insight -especially in tension- into the mechanical properties of the constituent materials (mortar and bricks), would be needed. As a matter of fact, classic NTM modelling appears too conservative in the unreinforced case and taking into account the actual masonry tensile strength would help in predicting better the experimental collapse load, which can be sensibly higher (more than 30\%).

2) For the reinforced case, a comprehensive characterization of the bond behavior in the different reinforcing systems appears crucial, even if requires extensive experimentation which goes beyond the aims of the present paper. As a matter of fact, the exact knowledge of the bond behavior is paramount to estimate the conventional tensile strength of the reinforcement, which is needed in limit analysis computations to predict properly the expected increase of the load bearing capacity. The limit analysis code proposed, thanks to its stability and computational efficiency, helps in quickly performing comprehensive sensitivity analyses, changing conventional tensile strength of the trusses representing the reinforcement, assuming a limited compressive strength (to figure out if crushing occurs) and a limited shear strength for the masonry elements. In case of reinforcement, indeed, the strength of the reinforcement is so high that sliding near abutments activates and a good match with experimentation is hardily obtainable with "à la Heyman" approaches. 
3) The extensive comparisons with experimental evidences reported highlight that, in case of FRP and SRG reinforcement, to account for sliding is crucial in order to obtain a good match with experimentation, even if the hypothesis of associated plasticity is not removed for the sake of simplicity. TRM case appears on the contrary well reproduced even with a model that disregards shear failure and masonry limited compressive strength, i.e. follows the classic thrust-line approach.

4) The sensitivity analyses carried out exhibit a relatively wide scatter of optimal data to arrive at solutions reproducing experimental evidences. This in turn suggests to assume strength parameters as random variables and opens the way for stochastic analysis, e.g. in the framework of Bayesian inference to improve the prior quite vague knowledge of the strength parameters and narrow then the original scatter when more measurements become available [45].

\section{Acknowledgements}

T.C.S. S.r.l. took of care the in situ application of the reinforcement systems and prepared the samples.

The materials characterization was performed at the Testing Laboratory for Materials, Structures and Constructions of Politecnico di Milano. Their financial support is gratefully acknowledged.

Part of the analyses were developed within the activities of Rete dei Laboratori Universitari di Ingegneria Sismica - ReLUIS for the research program funded by the Dipartimento di Protezione Civile.

Eng. Maurizio Acito is gratefully acknowledged for having put at disposal a licensed version of Straus7.

\section{References}

[1] Carozzi F.G., Poggi C., Bertolesi E., Milani G. Ancient masonry arches and vaults strengthened with TRM and FRP composites: Experimental evaluation. Composite Structures, Under review (2017).

[2] Kooharian A., Limit analysis of voussoir (segmental) and concrete arches. J. Am. Concrete Inst., 49 (12) (1952), 317-328.

[3] Heyman J., The safety of masonry arches. International Journal of Mechanical Sciences, 43 (1969), 209-224.

[4] Livesley R.K., Limit analysis of structures formed from rigid blocks. Int. J. Numer. Methods Eng., 12(12) (1978), 1853-1871

[5] Heyman J., The masonry arch. Ellis Horwood, Chicester, (1982).

[6] Oppenheim I. J., The masonry arch as a four-link mechanism under base motion. Earthquake Engineering and structural dynamics, 21 (11) (1992), 1005-1017.

[7] Bertolesi E., Milani G., Fedele R., Fast and reliable non-linear heterogeneous FE approach for the analysis of FRP-reinforced masonry arches. Composites Part B: Engineering, 80 (2016), 189-200.

[8] Lucchesi M., Padovani C., Pasquinelli G., Zani, N., On the Collapse of Masonry Arches, Meccanica, 32(4) (1997), 327-346.

[9] O’Dwyer D., Funicular analysis of masonry vaults. Computers \& Structures, 73 (1-5) (1999), 187-197.

[10] Gilbert M., Limit analysis applied to masonry arch bridges: state-of-the-art and recent developments. In Proc. 5th Int. Conf. Arch Bridg., Madeira, Portugal (2007). 
[11] Milani E., Milani G., Tralli A., Limit analysis of masonry vaults by means of curved shell Finite Elements and homogenization. International Journal of Solids and Structures, 45 (20) (2008), 5258-5288.

[12] Betti M., Drosopoulos, G. A., Stavroulakis, G. E. (2008). Two non-linear finite element models developed for the assessment of failure of masonry arches. Comptes Rendus Mécanique, 336(1-2) (2008), 42-53.

[13] Milani G., Upper bound sequential linear programming mesh adaptation scheme for collapse analysis of masonry vaults. Advances in Engineering Software, 79 (2015), 91110 .

[14] Sacco E., Some aspects on the statics of masonry aches. Masonry structures between mechanics and architecture, Springer International Publishing, Cham, 265-290 (2015).

[15] Chiozzi A., Milani G., Tralli A., A Genetic Algorithm NURBS-based new approach for fast kinematic limit analysis of masonry vaults, Computers \& Structures, 182 (2017), 187204.

[16] Faccio P., Foraboschi P., Siviero E., Masonry vaults reinforced with FRP strips (in Italian). L'Edilizia, 7-8 (1999), 44-50.

[17] Valluzzi M.R., Valdemarca M., Modena C., Behavior of brick masonry vaults strengthened by FRP laminates. J Compos Constr ASCE, (2001), 163-169.

[18] Foraboschi P., Strengthening of Masonry Arches with Fiber-Reinforced Polymer Strips. J Compos Constr ASCE, 8(3) (2004), 191-202.

[19] Borri A., Castori G., Corradi M., Intrados strengthening of brick masonry arches with composites materials. Composite Part B: Engineering, 42 (5) (2011), 1164-1172.

[20] Oliveira D. V., Basilio I., Lourenço P. B., Experimental behaviour of FRP strengthened masonry arches. Journal of Composites and Constructions, 14 (2010), 312-322.

[21] Rovero L., Focacci F., Stipo G., Structural behavior of arch models strengthened using fiber-reinforced polymer strips of different lengths. Journal of Composites for Construction, 17 (2013), 249-258.

[22] Baratta A., Corbi O., Stress analysis of masonry vaults and static efficacy of FRP repairs. International Journal of Solids and Structures, 44 (2007), 8028-8056.

[23] Caporale A., Luciano R., Rosati, L., Limit analysis of masonry arches with externally bonded FRP reinforcements. Computer Methods in Applied Mechanics and Engineering, 196(1) (2006), 247-260.

[24] Roca P., López-Almansa F., Miquel J., Hanganu, A. Limit analysis of reinforced masonry vaults. Eng. Struct., 29(3) (2007), 431-439.

[25] Briccoli Bati S., Rovero L., Towards a methodology for estimating strength and collapse mechanism in masonry arches strengthened with fibre reinforced polymer applied on external surfaces. Materials and Structures/Materiaux et Constructions, 41 (2008), 12911306.

[26] Marfia S., Ricamato M., Sacco E., Stress analysis of reinforced masonry arches. International Journal of Computational Methods in Engineering Science and Mechanics, 9 (2008), 77-90.

[27] Milani G., Milani E., Tralli A., Upper bound limit analysis model for FRP-reinforced masonry curved structures. Part II: Structural analyses. Computers and Structures, 87 (2009), 1534-1558.

[28] Cancelliere I., Imbimbo M., Sacco E., Experimental tests and numerical modeling of reinforced masonry arches. Engineering Structures, 32 (2010), 776-792. 
[29] Caporale A., Luciano R., Limit analysis of masonry arches with finite compressive strength and externally bonded reinforcement. Composites Part B: Engineering, 43 (2012), 3131-3145.

[30] Caporale A., Feo L., Luciano R., Limit analysis of FRP strengthened masonry arches via nonlinear and linear programming. Composites Part B: Engineering, 43 (2012), 439-446.

[31] Caporale A., Feo L., Luciano R., Penna R., Numerical collapse load of multi-span masonry arch structures with FRP reinforcement. Composites Part B: Engineering, 54 (2013), $71-$ 84.

[32] Drosopoulos G.A., Stavroulakis G.E., Massalas C.V., FRP reinforcement of stone arch bridges: Unilateral contact models and limit analysis. Composites Part B: Engineering, 38 (2007), 144-151.

[33] Briccoli Bati S., Fagone M., Rotunno T., Lower bound limit analysis of masonry arches with CFRP reinforcements: A numerical method. Journal of Composites for Construction, 17 (2013), 543-553.

[34] Baratta A., Corbi, O., Closed-form solutions for FRP strengthening of masonry vaults. Computers \& Structures, 147 (2015), 244-249.

[35] Chiozzi A., Milani G., Tralli A., Fast kinematic limit analysis of FRP-reinforced masonry vaults. I: A general Genetic Algorithm NURBS-based formulation. ASCE Journal of Engineering Mechanics, 143(9) (2017), Paper \#04017071.

[36] Chiozzi A., Milani G., Tralli A., Fast kinematic limit analysis of FRP-reinforced masonry vaults. II: Numerical simulations. ASCE Journal of Engineering Mechanics, 143(9) (2017), Paper \#04017072.

[37] Elmalich D., Rabinovitch O., Masonry and monolithic circular arches strengthened with composite materials - A finite element model. Computers and Structures, 87 (2009), 521533.

[38] Fedele R., Milani G., A numerical insight into the response of masonry reinforced by FRP strips. The case of perfect adhesion. Composite Structures, 92 (2010), 2345-2357.

[39] Fedele R., Milani G., Three-dimensional effects induced by FRP-from-masonry delamination. Composite Structures, 93 (7) (2011), 1819-1831.

[40] Fedele R., Milani G., Assessment of bonding stresses between FRP and masonry pillars during delamination tests. Composites Part B: Engineering, 43(4) (2012), 1999-2011.

[41] CNR-DT200. Guide for the design and construction of externally bonded FRP systems for strengthening existing structures. C.N.R., National Reaserch Council, Italy, Revision 8 March 2012.

[42] D'Ambrisi A., Mezzi M., Feo L., Berardi V.P., Analysis od masonry structues strengthened with polymeric net reinforced cementitious matrix materials. Composite Structures, 113 (1) (2014), 264-271.

[43] Alecci V., Misseri G., Rovero L., Stipo G., De Stefano M., Feo L., Luciano R., Experimental investigation on masonry arches strengthened with PBO-FRCM composite. Composites Part B, 100 (2016), 228-239.

[44] De Santis S., Roscini F., de Felice G., Retrofitting masonry vaults with basalt textile reinforced mortar. Key Engineering Materials, 747 (2017), 250-257.

[45] Sejnoha M., Janda T., Melzerova L., Nezerka V., Sejnoha J., Modeling glulams in linear range with parameters updated using Bayesian inference. Engineering Structures, 138 (2017), 293-307.

[46] Como M., Statics of Historic Masonry Constructions. vol. 1. Berlin, Heidelberg: Springer Berlin Heidelberg (2013). doi:10.1007/978-3-642-30132-2. 
[47] Huerta S. The Analysis of Masonry Architecture: A Historical Approach. Archit Sci Rev (2011).

[48] Del Piero G., Limit analysis and no-tension materials. Int. J. Plasticity, 14(1-3) (1998), 259-271.

[49] Sloan S.W., Kleeman P.W. ,Upper bound limit analysis using discontinuous velocity fields. Computer Methods in Applied Mechanics and Engineering (1995), 127 (1-4), 293 314.

[50] Olsen P.C., The Influence of the linearisation of the yield surface on the load bearing capacity of reinforced concrete slabs. Computer Methods in Applied Mechanics and Engineering (1998), 162, 351-358.

[51] Milani G., Lourenço P.B., Tralli A., Homogenised limit analysis of masonry walls, Part 1: Failure surfaces. Computers \& Structures (2006), 84: 166-180. 